Revista lus et Praxis, Año 19, № 2, 2013, pp. 335 - 368

ISSN 0717 - 2877

Universidad de Talca - Facultad de Ciencias Jurídicas y Sociales

"La obligación estatal de prevención a la luz del corpus iuris internacional

de protección de la mujer contra la violencia de género"

Juan Ramón Martínez Vargas - Giovanni Vega Barbosa

\title{
LA OBLIGACIÓN ESTATAL DE PREVENCIÓN A LA LUZ DEL CORPUS IURIS INTERNACIONAL DE PROTECCIÓN DE LA MUJER CONTRA LA VIOLENCIA DE GÉNERO*
}

\author{
STATE'S OBLIGATION TO PREVENT IN LIGHT OF THE INTERNATIONAL CORPUS IURIS \\ ON THE PROTECTION OF WOMEN AGAINST GENDER VIOLENCE
}

\author{
JuAn RAMÓn Martínez Vargas* \\ Giovanni Vega Barbosa ${ }^{* * *}$
}

\begin{abstract}
RESUMEN
Con fundamento en un análisis de la jurisprudencia internacional

aplicable, el presente artículo tiene como objetivo realizar una

aproximación casuística al fenómeno de la violencia intrafamiliar en el marco del

corpus juris internacional de protección de la mujer contra la violencia

que la afecta de manera especial o desproporcionada. Lo anterior, a la luz de la

obligación de prevención del Estado, haciendo un especial énfasis en el escenario interamericano de protección de los derechos humanos y tangencialmente, en el contexto de los sistemas europeo y universal. Este análisis nos permitirá sustentar la existencia de obligaciones adicionales y reforzadas de prevención, y proponer soluciones al dilema derivado de la aparente contradicción entre la persecución penal de la violencia intrafamiliar y la obligación de respeto por el derecho a la vida privada de la mujer.
\end{abstract}

\section{ABSTRACT}

The present article purports to make a theoretical approach to the phenomenon of "domestic" violence, within the framework of the international corpus juris on the protection of women against the type of violence that affects them in a special or disproportionate manner. The aforementioned will be analyzed in light of States'

\footnotetext{
* Trabajo recibido el 25 de junio y aprobado el 09 de octubre de 2013.

Este artículo es producto de la línea de investigación Derecho Internacional y Globalización del grupo de investigación de Derecho Internacional de la Facultad de Jurisprudencia de la Universidad del Rosario, Bogotá, Colombia.

** Doctor en Derecho de la Universidad Alfonso X El Sabio, Madrid, España. Máster en Cuestiones Actuales de Derecho Internacional de la Universidad Alfonso X El Sabio, Madrid, España. Abogado de la Universidad del Rosario, Bogotá, Colombia. Profesor Principal de carrera académica en Derecho Internacional de la Facultad de Jurisprudencia de la Universidad del Rosario. Correo electrónico: juan. martinez@urosario.edu.co.

*** Profesor de Derecho Internacional de la Universidad del Rosario, Coordinador del Grupo Interno de Trabajo Consultivo de la Dirección de Asuntos Jurídicos Internacionales del Ministerio de Relaciones Exteriores de la República de Colombia. Correo electrónico: giovanny.vega@cancilleria.gov.co.
} 
obligation of prevention, making particular emphasis on the Inter-American system on the protection of human rights and, transversally, of the European and Universal systems. This analysis will permit us to sustain the existence of additional and reinforced obligations of prevention, including a duty of surveillance, as well as to illustrate about the practical dilemmas which derive from the conflict between, on one hand, the obligation of prevention, and on the other, the obligation to respect women's right to private and family life.

Palabras Clave

Violencia contra la mujer, Obligación de prevención, Obligaciones reforzadas

KEYWORDS

Violence against women, Obligation of prevention, Strengthened obligations

\section{INTRODUCCIÓN}

Desde la perspectiva de su desarrollo en los tribunales internacionales y organismos especializados, la última década puede catalogarse como una de las más fructíferas en la protección de la mujer contra la violencia que de manera especial le afecta. En el campo de la responsabilidad internacional del Estado, los tribunales y organismos en los ámbitos interamericano -Comisión Interamericana ${ }^{1}$ y Corte Interamericana ${ }^{2}-$, europeo ${ }^{3}$ y universal ${ }^{4}$, han abordado dinámicas de discriminación que, aunque históricamente recurrentes, nunca habían encontrado un escenario de soporte convencional y consuetudinario suficiente que les permitiera generar reglas de protección claras y eficaces ${ }^{5}$. En

\footnotetext{
${ }^{1}$ La Comisión Interamericana de Derechos Humanos se ha pronunciado sobre la violencia contra la mujer en los casos: (Raquel Martín de Mejía vs. Perú, 1996); (X eY vs. Argentina, 1996); (Ana, Beatriz y Celia González Pérez vs. México, 2001); (María Eugenia Morales de Sierra vs. Guatemala, 2001); (María da Penha Maia Fernandes vs. Brasil, 2001); (Jessica Lenahan Gonzales y otros vs. EE.UU., 2011).

${ }^{2}$ La Corte Interamericana de Derechos Humanos se ha pronunciado sobre casos de violencia contra la mujer en: (Caso del Penal Miguel Castro Castro vs. Perú, 2006); (Caso González y otras ("Campo Algodonero") vs. México, 2009); (Caso De la Masacre de las Dos Erres vs. Guatemala, 2009); (Caso Fernández Ortega y otros. vs. México, 2010); (Caso Rosendo Cantú y otra vs. México, 2010).

${ }^{3}$ La Corte Europea de Derechos Humanos ha abordado la violencia contra la mujer en casos como: (M.C. vs. Bulgaria, 2003); (Bevacqua vs. Bulgaria, 2008); (Opuz vs. Turquía, 2009); (A vs. Croacia, 2010); entre otros.

${ }^{4}$ El Comité para la Eliminación de todas las formas de Discriminación contra la Mujer, en uso del Protocolo Facultativo de la Convención CEDAW ha emitido 11 comunicaciones de la cuales se destacan: (A.T. vs. Hungría, 2005); (A.S. vs. Hungría, 2006); (Sahide Goecke vs. Austria, 2007); (Fatma Yildirim vs. Austria, 2007).

${ }^{5}$ Byrnes, Andrew y BAtH, Eleanor, "Violence against Women, the Obligation of Due Diligence and the Optional Protocol to the Convention on the Elimination of All Forms of Discrimination against WomenRecent Developments", Human Rights Law Review, volumen. 8, número 3, 2008, pp. 517-533. En: http://www.deepdyve.com/lp/ou-press/violence-against-women-the-obligation-of-due-diligence-andthe-0vGmfxfE0o?shortRental=true [visitado el 13/07/2013].
} 
similar sentido, en el terreno de la responsabilidad penal individual internacional, las decisiones en el ámbito probatorio y sustancial han estado precedidas de valoraciones de género sin las cuales la exoneración de los responsables hubiera sido el denominador común ${ }^{6}$.

En este contexto, y a fin de dar cuenta del tratamiento de la violencia de género en los heterogéneos sistemas de protección de los derechos humanos, el presente artículo estará dividido en cinco secciones: (1) concepto de violencia contra la mujer y las posibilidades con las que se ha dotado al sistema interamericano de derechos humanos para prevenirla, combatirla y castigarla; (2) perspectiva de género, como herramienta sine qua non para visibilizar la real dimensión del problema y sus arraigos históricos; (3) obligaciones de debida diligencia del Estado en relación con la violencia contra la mujer y, en particular, el alcance de su deber de prevención; (4) respuesta al problema jurídico que surge con ocasión del conflicto entre la obligación de protección de los derechos de la mujer y el respeto y garantía de otras prerrogativas derivadas de los instrumentos internacionales. En este acápite nos referiremos a la aparente contradicción entre la obligación de persecución del delito de violencia intrafamiliar y el respeto por la vida privada de la mujer; y (5), finalmente, se formularán las conclusiones respectivas.

\section{Alcance del concepto de violencia contra}

LA MUJER Y SU JUSTICIABILIDAD EN EL SISTEMA INTERAMERICANO

DE PROTECCIÓN DE LOS DERECHOS HUMANOS

\section{El concepto de violencia contra la mujer}

Conforme al artículo 1 de la Convención Belem do Pará (en adelante CBDP):

"[...] Debe entenderse por violencia contra la mujer cualquier acción o conducta, basada en su género, que cause muerte, daño o sufrimiento físico, sexual o psicológico a la mujer, tanto en el ámbito público como el privado $[\ldots]^{\prime \prime}$.

El preámbulo de la CBDP señala que este instrumento encarna la preocupación del sistema interamericano por la violencia contra la mujer como una manifestación de las relaciones de poder históricamente desiguales entre hombres y mujeres, y concibe la eliminación de la violencia contra la mujer como

\footnotetext{
${ }^{6}$ En el caso del Tribunal Penal Internacional para Rwanda: (Fiscal vs. Jean Paul Akayesu, 1998); (Fiscal vs. Laurent Semanza, 2003). En el Tribunal Penal para la Antigua Yugoslavia: (Fiscal vs. Zejnil Delalic et al. (Celebici), 1998); (Fiscal vs. Kunarac et al- (Foca), 2001). En el caso del Tribunal Penal Internacional para Sierra de Sierra Leona: (Fiscal vs. Sesay et al., 2009).

7 Asamblea General de la Organización de Estados Americanos, Convención Interamericana para prevenir, sancionar y erradicar la violencia contra la mujer (Convención de Belem Do Para), 1994. En: http://www.oas.org/juridico/spanish/tratados/a-61.html [visitado el 13/07/2013].
} 
una condición indispensable para su desarrollo individual y social y su plena e igualitaria participación en todas las esferas de la vida ${ }^{8}$.

A la luz del tenor de esta disposición, la Corte Interamericana de Derechos Humanos (en adelante COIDH) ha señalado que el campo de aplicación ratione materiae de la $C B D P$ se refiere a las conductas que afectan los derechos humanos de la mujer y dirigidas en su contra por el hecho de serlo ${ }^{9}$, o que la afectan de manera desproporcionada ${ }^{10}$.

Bajo este orden de ideas, escapan a la esfera de protección de la norma en mención aquellas afectaciones a los derechos humanos de la mujer que se generan como consecuencia de un actuar indiscriminado y carente de un contenido discriminatorio en razón del género ${ }^{11}$. Aclarando este punto, y con ocasión de su decisión en los casos relativos a los hostigamientos, agresiones físicas y verbales y vulneración del derecho a la libertad de expresión de los funcionarios de las cadenas Globovisión y RCTV y sus instalaciones, la COIDH descartó el argumento de los representantes de las víctimas, según el cual, el porcentaje de mujeres afectadas en los ataques era indicativo del contenido de género de la violencia y, en consecuencia, la CBDP era aplicable ratione materiae. En su decisión de fondo, la Corte consideró necesario precisar que:

"[...] no toda violación de un derecho humano cometida en perjuicio de una mujer conlleva necesariamente una violación de las disposiciones de la Convención Belem Do Pará. Aunque las periodistas mujeres hayan sido agredidas en los hechos de este caso, en todas las situaciones lo fueron junto a sus compañeros hombres $(\ldots)^{\prime \prime 12}$.

Igualmente, en el caso de Perozo y otros con Venezuela, la COIDH, consideró que:

\footnotetext{
${ }^{8}$ El artículo 31 numeral $2^{\circ}$ de la Convención de Viena sobre el Derecho de los Tratados nos permite utilizar el preámbulo de un tratado a modo interpretativo, como parte del contexto a luz del cual se deben interpretar los términos del mismo.

${ }^{9}$ Penal Miguel Castro Castro con Perú, Corte Interamericana de Derechos Humanos, Responsabilidad Internacional del Estado por utilización excesiva de la fuerza, 25 de noviembre de 2006, Serie C No 160, 2006, párr. 276. En: http://www.corteidh.or.cr/docs/casos/articulos/seriec_160_esp. pdf [visitado el 16/07/2013].

${ }^{10}$ González y otras ("Campo Algodonero") con México, Corte Interamericana de Derechos Humanos, Responsabilidad internacional del Estado por la falta de diligencia en las investigaciones relacionadas a la desaparición y muerte de Claudia Ivette González, Esmeralda Herrera Monreal y Laura Berenice Ramos Monárrez, 16 de noviembre de 2009, Serie C № 205, 2009, párr. 75. En: http://www.corteidh. or.cr/tablas/fichas/campoalgodonero.pdf [visitado el 16/07/2013].

${ }^{11}$ En estos casos, la afectación deberá inscribirse en alguna de las categorías autónomas de la Convención Americana de Derechos Humanos y sin que este constituya un requisito sine qua non.

${ }^{12}$ Ríos y otros con Venezuela, Corte Interamericana de Derechos Humanos, Responsabilidad internacional del Estado por las restricciones a la libertad de expresión en perjuicio de 20 trabajadores del canal de televisión RCTV, 28 de enero de 2009, Serie C No 194, párr. 279. En: http://www.corteidh. or.cr/tablas/fichas/rios.pdf [visitado el 16/07/2013].
} 
"[...]. Los representantes no demostraron en qué sentido las agresiones fueron 'especialmente dirigidas contra las mujeres', ni explicaron las razones por las cuales las mujeres se convirtieron en un mayor blanco del ataque por su sexo. [...]. De esta manera, no ha sido demostrado que los hechos se basaran en el género o sexo de las presuntas víctimas ${ }^{\prime 13}$.

A nivel universal, la jurisprudencia del Comité de la Convención para la Eliminación de todas las Formas de Discriminación contra la Mujer (CEDAW por sus siglas en inglés) es ilustrativa respecto de los casos que constituyen eventos de violencia contra la mujer y que reflejan la situación histórica de discriminación contra la misma. En efecto, dentro de sus procedimientos cuasi jurisdiccionales, el Comité ha desaprobado legislaciones discriminatorias en la distribución de los bienes durante los procesos de divorcio ${ }^{14}$; la ausencia de mecanismos legales de protección de la mujer frente a la violencia doméstica o de otro tipo ${ }^{15}$; las prácticas de esterilización forzada ${ }^{16}$; y la discriminación respecto de los derechos de sucesión que le corresponden ${ }^{17}$.

Sin perjuicio de lo anterior, resulta conveniente observar que los precitados eventos no agotan las múltiples formas en que la violencia contra la mujer se ha manifestado históricamente. En este sentido, la doctrina coincide en afirmar que por violencia contra la mujer deben entenderse todos aquellos actos que de manera visible o invisible han logrado relegar y limitar a la mujer en el ejercicio pleno de sus derechos ${ }^{18}$. De esta forma, es posible definir la violencia contra

\footnotetext{
${ }^{13}$ Perozo y otros con Venezuela, Corte Interamericana de Derechos Humanos, Responsabilidad internacional del Estado por restricciones a la libertad de expresión, 28 de enero de 2009, Serie C № 195, 2009, párr. 295. En: http://www.corteidh.or.cr/tablas/fichas/perozo.pdf [visitado el 16/07/2013].

${ }^{14}$ Comité para la Eliminación de la Discriminación contra la Mujer, Comunicación № 1/2003, B.J. contra Alemania, 2004. En: http://www.worldcourts.com/cedaw/eng/decisions/2004.07.14_BJ_v_Germany.htm [visitado el 18/07/2013].

${ }^{15}$ Comité para la Eliminación de la Discriminación contra la Mujer, Comunicación № 2/2003, A. T. contra Hungría, 2005. En: http://www.un.org/womenwatch/daw/cedaw/protocol/decisions-views/ CEDAW\%20Decision\%20on\%20AT\%20vs\%20Hungary\%20Spanish.pdf [visitado el 17/07/2013].

${ }^{16}$ Comité para la Eliminación de la Discriminación contra la Mujer, Comunicación № 4/2004, A. S. contra Hungría, 2006. En: http://www.un.org/womenwatch/daw/cedaw/protocol/decisions-views/ Decision\%204-2004\%20-\%20Spanish.pdf [visitado el 17/07/2013].

${ }^{17}$ Comité para la Eliminación de la Discriminación contra la Mujer, Comunicación № 7/2005, Cristina Muñoz-Vargas y Sainz de Vicuña contra España, 2007. En: http://www.equidad.scjn.gob.mx/IMG/pdf/ Caso_Munoz_Vargas_v-_Espana_Inadmisible_.pdf [visitado el 17/07/2013].

${ }^{18}$ Bustamante Arango, Diana Marcela y Vásquez Henao, Paola Andrea, "La Convención Belém Do Pará un balance de su aplicación en la jurisprudencia de la Corte Interamericana, a 16 años de su entrada en vigor", Civilizar Ciencias Sociales y Humanas, volumen 11, número 20, 2011, pp. 15-36. En: http:// www.usergioarboleda.edu.co/civilizar/civilizar-20/LA\%20CONVENCI\%C3\%93N\%20BEL\%C3\%89M. pdf [visitado el 22/12/2011]. Ver también: Comité para la Eliminación de la Discriminación contra la Mujer, Recomendación general № 19, 1992. En su numeral primero refiere que la violencia contra la mujer es una forma de discriminación que impide gravemente que goce de derechos y libertades en pie de igualdad con el hombre.
} 
la mujer como una forma de discriminación contra la misma ${ }^{19}$, categoría que es definida por el artículo 1 de la Convención para la Eliminación de todas las formas de Discriminación contra la Mujer, en los siguientes términos:

"[...] discriminación contra la mujer, denotará toda distinción o restricción basada en el sexo que tenga por objeto o por resultado menoscabar o anular el reconocimiento, goce o ejercicio por la mujer [...] de los derechos humanos y libertades fundamentales $[\ldots]^{\prime \prime 20}$.

Sin perjuicio de lo anterior, el reconocimiento de la relación entre la prohibición de discriminación y la violencia contra la mujer ha tenido un desarrollo tardío en la jurisprudencia de los tribunales regionales de derechos humanos y, especialmente, en la CEDH. En efecto, aunque la CEDH había emitido decisiones significativas en relación con la violencia de género, particularmente en lo referente al deber de garantía frente a los actos de violencia sexual perpetrados por particulares, sus decisiones en los casos de violencia contra la mujer omitían cualquier articulación entre las afectaciones a la integridad personal y vida de las mujeres, con la prohibición de discriminación prevista en el artículo 14 del convenio europeo ${ }^{21}$.

En ese sentido, el caso Opuz con Turquía representa un hito en la aproximación del tribunal a los casos de violencia contra la mujer. En este caso, a la luz de las recomendaciones generales y decisiones del Comité de Derechos Humanos, y atendiendo a los desarrollos propiciados por la CBDP en el continente americano, la Corte encontró que, al establecer un balance entre la obligación de proteger los derechos de la víctima de violencia intrafamiliar y la obligación de no interferir en la vida marital de la misma, Turquía había favorecido la mediación con la pareja y la caracterización del problema como un asunto privado y doméstico. En consecuencia, las autoridades habrían adoptado una posición pasiva como reflejo de una concepción permisiva y discriminatoria de la violencia contra la mujer.

${ }^{19}$ Comité para la Eliminación de la Discriminación contra la Mujer, Recomendación General № 19, 1992, párr. 6. En: http://www.ipu.org/splz-e/cuenca10/cedaw_19.pdf [visitado el 17/07/2013].

${ }^{20}$ Comité para la Eliminación de la Discriminación contra la Mujer, Convención sobre la Eliminación de Todas las Formas de Discriminación contra la Mujer (CEDAW), 1979. En: http://www2.ohchr.org/ spanish/law/cedaw.htm [visitado el 17/07/2013].

${ }^{21}$ Londono, Patricia, "Developing Human Rights Principles in Cases of Gender-based Violence: Opuz $v$ Turkey in the European Court of Human Rights", Human Rights Law Review, volumen 9, número 4, 2009, pp. 657-667. En: http://www.deepdyve.com/lp/oxford-university-press/developing-humanrights-principles-in-cases-of-gender-based-violence-0JsWtsQLNn [visitado el 13/07/2013]. A modo de ejemplo, en el caso de $\mathrm{MC}$ con Bulgaria es posible observar que aun cuando las deficiencias del sistema legal búlgaro para tratar adecuadamente casos de acceso carnal violento fueron analizados a la luz del artículo 3, relativo a la prohibición de trato inhumano o degradante, no se abordó el análisis del problema en relación con la discriminación contra la mujer en la protección de sus derechos. 
De otra parte, el Comité de la CEDAW ha calificado la violencia intrafamiliar como una categoría específica de la violencia contra la mujer con presencia en todas las sociedades y que somete a la mujer de todas las edades a diferentes tipos de vejámenes, inter alia, lesiones, violaciones, violencia mental, etc. En relación con las causas de esta violencia, el Comité señala:

"23. La violencia en la familia es una de las formas más insidiosas de violencia contra la mujer. Existe en todas las sociedades... La falta de independencia económica obliga a muchas mujeres a permanecer en situaciones violentas. La negación de sus responsabilidades familiares por parte de los hombres puede ser una forma de violencia y coerción. Esta violencia compromete la salud de la mujer y entorpece su capacidad de participar en la vida familiar y en la vida pública en condiciones de igualdad"22.

En consonancia con lo anterior, Dragiewicz y Lindgren rechazan la aplicación de estándares formales de igualdad en los análisis relativos a las acciones afirmativas adoptadas con miras a garantizar la protección de la mujer contra la violencia intrafamiliar. De esta forma, en su crítica a la decisión de la Tercera Corte de Apelaciones del Distrito de California en Woods con Horton ${ }^{23}$, decisión que apeló a la simetría entre sexos para condenar la financiación pública diferencial de los refugios para mujeres víctimas de violencia intrafamiliar, las precitadas tratadistas encontraron sustentos estadísticos para señalar, en los siguientes términos, que la violencia intrafamiliar afecta desproporcionalmente a la mujer:

"[...] Specifically, in its formal equality review, the court failed to sufficiently consider the gendered nature of domestic violence and the social and political context in which violence against women occurs. Women are battered much more frequently, suffer much greater injuries, and are at much higher risk of being killed by their batterer than their male counterparts, particularly at separation. Further, women who are battered are in greater need of the specific services offered by shelters because of the profoundly gendered nature of battering, wherein women and hildren bear substantial risk of homicide, assault, rape, and stalking following separation from an abuser, whereas men do not. Women also have fewer economic resources and often are more dependent on their abusers than men due to women's persistently lower income and greater participation in child care" ${ }^{\prime \prime 2}$.

\footnotetext{
${ }^{22}$ Comité para la Eliminación de la Discriminación contra la Mujer, cit. nota n. 18, párr. 23.

${ }^{23}$ Woods con Horton, California Third District Court of Appeal, Domestic Violence, 14 de octubre de 2008, 84 Cal. Rptr. 3d 332, 349.

${ }^{24}$ Dragiewicz, Molly; Lindgreen, Yvonne, "The gendered nature of domestic violence: statistical data for lawyers considering equal protection analysis", Journal of Gender, Social Policy \& the Law, vol. 17, number 2, 2009, p. 231. En: http://xa.yimg.com/kq/groups/20981664/1536011611/name/ Dragiewicz+Lindgren+2009.pdf [visitado el 13/07/2013]. Como soporte a los hallazgos de las autoras ver: Swan, Suzanne C. y SNOW, David L., "A Typology on Women's Use of Violence in Intimate Relationships", Violence against women, volumen 8, número 3, 2002, pp. 286-319. En: http://people.cas. sc.edu/swansc/1.swan_web_articles/2002_SwanSnow_TypologyWomensUseOfViolence.pdf [visitado el 18/07/2013]; TJADEN, Patricia y ThoENnEs, Nancy, "Prevalence. Incidence and Consequences of Violence
} 
De esta forma, y como se observa en la segunda parte del presente escrito, al constatar que la violencia intrafamiliar afecta de manera desproporcional a la mujer, la aplicación de un enfoque diferencial y de género en el análisis de la violencia contra la mujer es un requisito esencial de su comprensión y visibilización.

\section{La justiciabilidad de la violencia \\ contra la mujer en el Sistema Interamericano de Protección de los Derechos Humanos (en adelante SIPDH)}

Bajo la teoría general de la responsabilidad internacional del Estado, éste sólo puede ser encontrado responsable internacionalmente cuando se constate que la conducta concernida: (i) es atribuible al Estado, y (ii) constituye una violación de una obligación internacional oponible al $\mathrm{mismo}^{25}$. Sin embargo, el régimen general dice poco en relación con las condiciones y limitaciones para que la violencia contra la mujer pueda ser conocida por un tribunal internacional de derechos humanos, en particular, en el SIPDH.

En efecto, el sistema de peticiones individuales en el SIPDH ha presenciado debates que no se agotan en el contenido de la obligación ${ }^{26} \mathrm{o}$ la atribución de los actos de particulares al Estado ${ }^{27}$ y, por el contrario, se expanden a la capacidad de las Cortes para conocer de violaciones a la CBDP. En este sentido, surge como imperativo dogmático establecer una diferencia entre el contenido y alcance del concepto violencia contra la mujer y la capacidad de los órganos jurisdiccionales internacionales para conocerla.

El presente problema jurídico fue definido por la COIDH con ocasión de su decisión en la demanda presentada en contra de los Estados Unidos Mexicanos, en virtud de un supuesto incumplimiento a sus deberes de prevención e investigación en la desaparición y posterior muerte de tres mujeres (2 de ellas niñas), cuyos cuerpos fueron encontrados en un campo algodonero de Ciudad Juárez en noviembre de 2001. Lo anterior, en un contexto de violencia generalizada contra la mujer.

\footnotetext{
Against Women: findings from the national violence against women survey", Research in Brief, 2, 1998, 16 pp. En: https://www.ncjrs.gov/pdffiles/172837.pdf [visitado el 18/07/2013].

${ }^{25}$ Organización de las Naciones Unidas, Proyecto de artículos sobre la responsabilidad del Estado por hechos internacionalmente ilícitos con sus comentarios, 2001. En: http://untreaty.un.org/ilc/texts/ instruments/english/commentaries/9_6_2001.pdf [visitado el 20/11/2011].

${ }^{26}$ Ríos y otros con Venezuela, Corte Interamericana de Derechos Humanos, cit. nota n. 12; Perozo y otros con Venezuela, Corte Interamericana de Derechos Humanos, cit. nota n. 13.

${ }^{27}$ Ver en este trabajo la sección III, parágrafo 3, literal a).
} 
Según el Estado mexicano, el artículo 12 de la $C B D P^{28}$ únicamente autorizaba a la $\mathrm{CIDH}$ para conocer de las violaciones al artículo $7^{29}$ bajo el sistema de peticiones individuales. De esta forma, la competencia de la COIDH para conocer del instrumento en mención quedaría circunscrita a su función consultiva.

La COIDH resolvió la excepción preliminar en comento apelando a los criterios interpretativos consagrados en el artículo 31 de la Convención de Viena sobre el Derecho de los Tratados, así como al principio pro homine o pro persona, rector de la interpretación de los tratados de derechos humanos. De esta forma, la COIDH concluyó que, conforme a una interpretación literal ${ }^{30}$, sistemática ${ }^{31}$ y teleológica o de efecto útili ${ }^{32}$, tenía competencia en relación con las violaciones a los deberes contenidos en el artículo 7 de la CBDP.

Lo anterior, en razón a que, aun cuando el texto del artículo 12 sólo hace mención expresa de la CIDH, lo hace en el contexto del sistema de peticiones

28 "Artículo 12. Cualquier persona o grupo de personas, o entidad no gubernamental legalmente reconocida en uno o más Estados miembros de la Organización, puede presentar a la Comisión Interamericana de Derechos Humanos peticiones que contengan denuncias o quejas de violación del artículo 7 de la presente Convención por un Estado Parte, y la Comisión las considerará de acuerdo con las normas y los requisitos de procedimiento para la presentación y consideración de peticiones estipulados en la Convención Americana sobre Derechos Humanos y en el Estatuto y el Reglamento de la Comisión Interamericana de Derechos Humanos".

29 "Artículo 7. Los Estados Partes condenan todas las formas de violencia contra la mujer y convienen en adoptar, por todos los medios apropiados y sin dilaciones, políticas orientadas a prevenir, sancionar y erradicar dicha violencia y en llevar a cabo lo siguiente: a) abstenerse de cualquier acción o práctica de violencia contra la mujer y velar por que las autoridades, sus funcionarios, personal y agentes e instituciones se comporten de conformidad con esta obligación; b) actuar con la debida diligencia para prevenir, investigar y sancionar la violencia contra la mujer; c) incluir en su legislación interna normas penales, civiles y administrativas, así como las de otra naturaleza que sean necesarias para prevenir, sancionar y erradicar la violencia contra la mujer y adoptar las medidas administrativas apropiadas que sean del caso; d) adoptar medidas jurídicas para conminar al agresor a abstenerse de hostigar, intimidar, amenazar, dañar o poner en peligro la vida de la mujer de cualquier forma que atente contra su integridad o perjudique su propiedad; e) tomar todas las medidas apropiadas, incluyendo medidas de tipo legislativo, para modificar o abolir leyes y reglamentos vigentes, o para modificar prácticas jurídicas o consuetudinarias que respalden la persistencia o la tolerancia de la violencia contra la mujer; f) establecer procedimientos legales justos y eficaces para la mujer que haya sido sometida a violencia, que incluyan, entre otros, medidas de protección, un juicio oportuno y el acceso efectivo a tales procedimientos; $g$ ) establecer los mecanismos judiciales y administrativos necesarios para asegurar que la mujer objeto de violencia tenga acceso efectivo a resarcimiento, reparación del daño u otros medios de compensación justos y eficaces, $y, h$ ) adoptar las disposiciones legislativas o de otra índole que sean necesarias para hacer efectiva esta Convención".

${ }^{30}$ González y otras ("Campo Algodonero") con México, Corte Interamericana de Derechos Humanos, cit. nota n. 10, párr. 40-42.

${ }^{31}$ González y otras ("Campo Algodonero") con México, Corte Interamericana de Derechos Humanos, cit. nota n. 10, párr. 54-55.

${ }^{32}$ González y otras ("Campo Algodonero") con México, Corte Interamericana de Derechos Humanos, cit. nota n. 10, párr. 60-64. 
individuales contenido en los artículos 44 a 51 de la Convención Americana, los cuales avalan el sometimiento de un caso a la Corte una vez agotado el trámite ante la $\mathrm{CIDH}$. Sin perjuicio de lo anterior, la $\mathrm{COIDH}$ recordó que, la $C B D P$ en general, y el artículo 12 en particular, materializan el deseo americano de reforzar el sistema de peticiones individuales en lo que a la violencia contra la mujer concierne, aspiración en la que la jurisdicción contenciosa de la $\mathrm{COIDH}$ juega un papel preponderante.

La fuerza de este pronunciamiento y la interiorización de la ratio decidendi del mismo ha quedado evidenciada en la jurisprudencia posterior de la $\mathrm{COIDH}$, la cual demuestra que los Estados han procedido al retiro de la excepción preliminar de falta de competencia de la COIDH sin esperar a un pronunciamiento sobre la procedencia de la misma ${ }^{33}$.

\section{DIMENSIÓN HISTÓRICA Y SOCIAL DE LA VIOLENCIA CONTRA LA MUJER EN EL MARCO DEL DEBER DE PREVENCIÓN}

El hombre aprende a través de su experiencia con el mundo social que lo rodea, es decir, aprende a la vez que socializa. En este proceso la formación de identidad y el reconocimiento de nuestras limitaciones no opera de forma libre; estos procesos varían en función de la sociedad en la que formamos nuestra identidad ${ }^{34}$.

La anterior manifestación cobra relevancia en el marco de la violencia contra la mujer, cuando se reconoce que, históricamente, la atribución de características, valores y roles de cada uno de los $\operatorname{sexos}^{35}$, no se hizo de forma equitativa $y$, por el contrario, los roles asignados a las mujeres tuvieron menor valor ${ }^{36}$.

Al respecto, el Comité de la CEDAW manifiesta en su Recomendación General 19 que:

\footnotetext{
${ }^{33}$ Fernández Ortega y otros con México, Corte Interamericana de Derechos Humanos, Responsabilidad internacional por violación sexual cometida por agentes militares, 30 de agosto de 2010, Serie C № 216, 2010, párr. 11. En: http://www.corteidh.or.cr/docs/casos/articulos/seriec_215_esp. pdf [visitado el 16/07/2013]; Rosendo Cantú y otra con México, Corte Interamericana de Derechos Humanos, Responsabilidad internacional del Estado por violación sexual y tortura en perjuicio de la señora Rosendo Cantú, 31 de agosto de 2010, Serie C No 216, 2010, párr. 13. En: http://www.corteidh.or.cr/docs/casos/ articulos/seriec_216_esp. pdf [visitado el 16/07/2013].

${ }^{34}$ Comisión Interamericana de Derechos Humanos, Informe No 5/96, 1996. En: http://www1.umn. edu/humanrts/cases/1996/Speru5-96.htm [visitado el 15/07/2013].

${ }^{35}$ Esto no quiere decir que el género sea equiparable al sexo. El último de estos conceptos aborda simplemente las diferencias de carácter biológico y, por tanto, su desarrollo e importancia es ajeno al presente texto.

${ }^{36}$ Comisión Interamericana de Derechos Humanos, Informe de la Comisión Interamericana sobre la Condición de la Mujer en las Américas, 1998. En: http://www.cidh.org/countryrep/Mujeres98/Mujeres98.htm [visitado el 15/07/2013].
} 
"11. Las actitudes tradicionales, según las cuales se considera a la mujer como subordinada o se le atribuyen funciones estereotipadas perpetúan la difusión de prácticas que entrañan violencia o coacción, como la violencia y los malos tratos en la familia, los matrimonios forzosos, el asesinato por presentar dotes insuficientes, los ataques con ácido y la circuncisión femenina. Esos prejuicios y prácticas pueden llegar a justificar la violencia contra la mujer como una forma de protección o dominación. El efecto de dicha violencia sobre su integridad física y mental es privarla del goce efectivo, el ejercicio y aun el conocimiento de sus derechos humanos y libertades fundamentales. Si bien en esta observación se hace hincapié en la violencia real o las amenazas de violencia, sus consecuencias básicas contribuyen a mantener a la mujer subordinada, a su escasa participación en política y a su nivel inferior de educación y capacitación y de oportunidades de empleo"37.

Señalado lo anterior, toda aproximación a la prevención de la violencia contra la mujer precisará de un enfoque o perspectiva de género, entendido éste como un concepto complejo que alude "tanto al conjunto de características y comportamientos, como a los roles, funciones y valoraciones impuestas dicotómicamente a cada sexo a través de procesos de socialización (... (1"38. En este sentido, el género es conformado socialmente y se refiere al modo de ser hombre o mujer en una cultura determinada ${ }^{39}$. La familia, lejos de estar exenta a esta dinámica de imposición, replica la distribución de roles en función del sexo, la edad y el poder ${ }^{40}$.

A su turno la perspectiva de género es entendida como aquella forma de observar la realidad:

"[...] con base en las variables sexo y género, que permite identificar los diferentes papeles y tareas que llevan a cabo los hombres y las mujeres en una sociedad, así como la asimetría y las relaciones de poder e inequidades [... $]^{\prime 41}$.

Otros trabajos definen la perspectiva de manera similar, como:

"[...] la forma de observar la realidad con base en las variables 'sexo' y 'género' y sus manifestaciones en un contexto geográfico, ético e histórico determinado. Este enfoque

\footnotetext{
${ }^{37}$ Comité para la Eliminación de la Discriminación contra la Mujer, cit. nota n. 19, párr. 11.

${ }^{38}$ FACIO MontejO, Alda; "Feminismo, Género y Patriarcado", en Violencia contra las mujeres, p. 13. En: http://cidem-ac.org/sitio/documentos/_tastydir/do.php?download=\%2Fhome\%2Fpangea $\% 2 \mathrm{Fp}$ ublic_html\%2Fsitio $\% 2$ Fdocumentos $\% 2$ Fbibliovirtual\%2FVIOLENCIA $\% 20$ CONTRA $\% 20$ LAS $\% 20$ MUJERES\%2FGenero\%2C\%20Derecho\%20y\%20Patriarcado.pdf, [visitado el 15/07/2013].

${ }^{39}$ Secretaría Ejecutiva de la Comisión Interamericana para el Control del Abuso de Drogas (CICAD) y Dirección General del Instituto Interamericano del Niño (IIN), La perspectiva de género como modelo de análisis de la violencia familiar y el consumo de alcohol y otras drogas, 1996. En: http://www.cicad. oas.org/reduccion_demanda/esp/Mujer/COSTARIC1996-rev.pdf [visitado el 13/07/2013].

${ }^{40}$ Comisión Interamericana de Derechos Humanos, cit. nota n. 36.

${ }^{41}$ Programa de las Naciones Unidas para el Desarrollo, Integración del enfoque de género en los proyectos del PNUD, 2009. En: http://www.pnud.org.co/img_upload/196a010e5069f0db02ea92181 c5b8aec/ldeas\%20basicas.pdf [visitado el 18/09/2010].
} 
permite visualizar y reconocer la existencia de relaciones de jerarquía y desigualdad entre hombres y mujeres expresadas en opresión, injusticia, subordinación y discriminación, mayoritariamente hacia las mujeres" ${ }^{\prime \prime 2}$.

La perspectiva de género contribuye al entendimiento de la verdadera dimensión de la violencia contra la mujer al demostrar que, más allá de un problema de afectación a la integridad personal de la mujer, refleja un problema de discriminación ${ }^{43}$.

Sobre el particular es preciso indicar que, al menos en el continente americano, históricamente la mujer se ha visto sujeta a diversas formas de violencia física, psicológica y sexual ${ }^{44}$, tanto en tiempos de paz como de conflicto armado $^{45}$, situaciones que han repercutido en una condición reconocida de vulnerabilidad. Estas formas se materializan en una serie de comportamientos de la sociedad y de la misma mujer, los cuales tienden a invisibilizar la real dimensión de la problemática.

De esta forma, y según se desprende del análisis de la jurisprudencia universal y regional, la aplicación de una perspectiva de género en el análisis de la violencia contra la mujer ha tenido como consecuencia práctica el reconocimiento de la existencia de deberes reforzados de debida diligencia para el Estado, así como de deberes adicionales de prevención. En consecuencia, junto con los deberes tradicionales de debida diligencia, el presente trabajo defiende la existencia de un deber adicional en relación con la violencia intrafamiliar: el de seguimiento.

En el caso de las obligaciones de regulación del Estado y, en particular, la obligación de tipificar la violencia contra la mujer, se hace necesario notar que, históricamente, uno de los principales obstáculos para el acceso de las mujeres a la justicia ha sido la legislación civil y penal basadas en concepciones estereotipadas del papel de la mujer en la sociedad ${ }^{46}$. Estas concepciones han

\footnotetext{
${ }^{42}$ Secretaría Ejecutiva de la Comisión Interamericana para el Control del Abuso de Drogas (CICAD) y Dirección General del Instituto Interamericano del Niño (IIN), cit. nota n. 39, p. 8.

${ }^{43}$ GoldsCheID, Julie, "Domestic and Sexual Violence as Sex Discrimination: Comparing American and International Approaches", Thomas Jefferson Law Review, vol. 8, Number 3, 2006, pp. 355-398. En: http:// www.tjeffersonlrev.org/sites/tjeffersonlrev.org/files/28-03-03-Goldscheid.pdf [visitado el 13/07/2013]; McQuigG, Ronagh J.A., "Domestic Violence and the Inter-American Commission on Human Rights: Jessica Lenahan (Gonzales) v United States", Human Rights Law Review, volumen 12, número 1, 2012. En: http://www.deepdyve.com/lp/ou-press/domestic-violence-and-the-inter-american-commission-onhuman-rights-NvMV0g65Yx?shortRental=true [visitado el 13/07/2013].

${ }^{44}$ Comisión Interamericana de Derechos Humanos, cit. nota n. 36.

${ }^{45}$ Comisión Interamericana de Derechos Humanos, Las Mujeres Frente a la Violencia y la Discriminación Derivadas del Conflicto Armado en Colombia, 2006. En: http://www.cidh.org/countryrep/colombiamujeres06sp/informe\%20mujeres\%20colombia\%202006\%20espanol.pdf [visitado el 15/07/2013].

${ }^{46}$ Comisión Interamericana de Derechos Humanos, Acceso a la Justicia para las Mujeres Víctimas de Violencia en las Américas, 2007, párr. 15. En: http://www.cidh.oas.org/women/Acceso07/indiceacceso. htm [visitado el 15/07/2013].
} 
Ilevado a que algunos países del continente negaran, hasta hace algunos años, la configuración del injusto en el acceso carnal violento, cuando lo cometía el hombre en contra de su esposa ${ }^{47}$. En estos casos, el poder judicial defendía la reivindicación del ejercicio de un legítimo derecho del esposo.

En este sentido, la CIDH ha criticado que en la redacción de los tipos penales en materia sexual se incluyan valores tales como la honra, el pudor social, la doncellez, la castidad, las buenas costumbres y peor aún, que dichos valores prevalezcan sobre bienes jurídicos como la integridad psicofísica y la libertad sexual. Estas consideraciones impiden la debida protección legal a la víctimas de tales delitos ${ }^{48}$ y propician una criminalización moralizadora en vez de enfocada en la protección de los bienes jurídicos ${ }^{49}$.

En el particular caso de la violencia intrafamiliar, la $\mathrm{CIDH}$ ha señalado que la legislación que deja de lado los eventos de violencia que ocurren en contextos diferentes al doméstico constituye uno de los obstáculos más importantes para el acceso de la mujer a la justicia ${ }^{50}$. La anterior omisión ha sido criticada de manera reiterada y enfática por parte de la $\mathrm{CIDH}$, pues genera altos índices de impunidad ${ }^{51}$ y le resta eficacia al sistema judicial respecto de las diversas formas en que se materializa la violencia contra la mujer.

En atención a las consideraciones precedentes, y aunque las limitaciones de espacio no nos permiten profundizar sobre el tema, el presente trabajo defiende la tipificación del tipo de violencia intrafamiliar por encima del de violencia doméstica. Lo anterior, por considerar que esta última nominación del tipo penal restringe la configuración del injusto a los actos de violencia perpetrados en el ámbito doméstico, excluyéndola en relación con las demás agresiones generadas en torno a la relación familiar ${ }^{52}$.

\footnotetext{
${ }^{47}$ Primera Sala de la Suprema Corte de Justicia de la Nación, Violación sexual entre cónyuges, 16 de noviembre de 2005, Gaceta del Semanario Judicial de la Federación, Núm. 77, 2005, p. 17. En: http:// ius.scjn.gob.mx/documentos/tesis/206/206112.pdf [visitado el 15/07/2013].

${ }^{48}$ Comisión Interamericana de Derechos Humanos, cit. nota n. 36.

${ }^{49}$ Benites SÁnchez, Santiago, Derecho Penal Peruano: Comentarios a la Parte Especial, Imprenta del departamento de prensa y publicaciones de la Guardia Civil, Lima, 1959, p. 193.

${ }^{50}$ Comisión Interamericana de Derechos Humanos, cit. nota n. 46.

${ }^{51}$ Comisión Interamericana de Derechos Humanos, Segundo Informe sobre la Situación de los Derechos Humanos en Perú, 2000. En: http://www.cidh.org/countryrep/peru2000sp/indice.htm [visitado el 15/07/2013]; Comisión Interamericana de Derechos Humanos, Justicia e Inclusión Social: Ios desafíos de la democracia en Guatemala, 2003. En: http://www.cidh.org/countryrep/Guatemala2003sp/indice. htm [visitado el 15/07/2013].

${ }^{52}$ Véase en este sentido: Organización Panamericana de la Salud, Modelo de Leyes y Políticas sobre Violencia Intrafamiliar contra las Mujeres, 2004. En: http://www1.paho.org/Spanish/AD/GE/LeyModelo. pdf [visitado el 16/07/2013].
} 
Finalmente, en escenarios ajenos al campo de atención específico de este trabajo, se ha aplicado la perspectiva de género para determinar que el acceso carnal no requiere necesariamente la introducción del órgano viril dentro de los órganos genitales de la mujer ${ }^{53}$; que los crímenes sexuales no están limitados a la genitalidad ${ }^{54}$; que las secuelas físicas no son un criterio confiable porque la mujer y en especial la niña, suelen caer en estados de congelación que anulan su resistencia (frozen fright ${ }^{55}$; que la falta de protesta no puede ser entendida como consentimiento cuando existe un contexto de miedo ${ }^{56}$; finalmente, que la vida sexual previa de la víctima no constituye un fundamento para valorar la configuración o no de la afectación a la integridad sexual. Al respecto las Reglas de Procedimiento y Prueba del Estatuto de La Corte Penal Internacional, establecen en su Regla 70, relativa a los Principios de la prueba en casos de violencia sexual, que en casos de violencia sexual, la Corte se guiará por los siguientes principios y, cuando proceda, los aplicará: (a) El consentimiento no podrá inferirse de ninguna palabra o conducta de la víctima cuando la fuerza, la amenaza de la fuerza, la coacción o el aprovechamiento de un entorno coercitivo hayan disminuido su capacidad para dar un consentimiento voluntario y libre; (b) El consentimiento no podrá inferirse de ninguna palabra o conducta de la víctima cuando ésta sea incapaz de dar un consentimiento libre; (c) El consentimiento no podrá inferirse del silencio o de la falta de resistencia de la víctima a la supuesta violencia sexual; (d) La credibilidad, la honorabilidad o la disponibilidad sexual de la víctima o de un testigo no podrán inferirse de la naturaleza sexual del comportamiento anterior o posterior de la víctima o de un testigo ${ }^{57}$.

\footnotetext{
${ }^{53}$ Fiscal con Sesay, Kallon y Gbao, Tribunal Penal Internacional para Sierra Leona, Crímenes Internacionales de género, 26 de octubre de 2009, Caso № SCSL-04-15-T, 2009, párr. 146. En: http://www. sc-sl.org/LinkClick.aspx?fileticket=CGgVJRfNF7M\%3D\&tabid=218 [visitado el 17/07/2013].

${ }^{54}$ Gómez Tomillo, Manuel, "Derecho Penal Sexual y Reforma Legal: Análisis desde una perspectiva político criminal", Revista Electrónica de Ciencia Penal y Criminología, núm. 07-04, 2005. En: http:// criminet.ugr.es/recpc/07/recpc07-04.pdf [visitado el 16/07/2013].

${ }^{55} \mathrm{MC}$ con Bulgaria, Corte Europea de Derechos Humanos, Obligación del Estado de investigar efectivamente y tipificar adecuadamente la violación sexual, 4 de diciembre de 2003, Demanda № 39272/98, 2003, párr. 70, 180-2. En: http://www.equidad.scjn.gob.mx/IMG/pdf/Caso_M-C-_v-_Bulgaria_-_Ingles. pdf [visitado el 17/07/2013].

${ }^{56}$ Fiscal con Kunarac, Kovac, Vukovic, Tribunal Penal Internacional para la Antigua Yugoslavia, Crímenes sexuales cometidos en un contexto de conflicto armado, 22 de febrero de 2001, Caso No IT-96-23-T \&IT-96-23/1-T, 2001, párr. 446, 452. En: http://www.icty.org/x/cases/kunarac/tjug/en/kun-tj010222e. pdf [visitado el 17/07/2013].

${ }^{57}$ Corte Penal Internacional, Las Reglas de Procedimiento y Prueba, 2000. En: http://www1.umn.edu/ humanrts/instree/S-iccrulesofprocedure.html. [visitado el 13/07/2013].
} 


\section{Obligaciones del Estado en relación con la violencia contra la mujer: el}

\section{DEBER DE PREVENCIÓN DE LOS ACTOS DE TERCEROS}

En el ámbito de la violencia contra la mujer, el artículo 7.b de la CBDP establece de manera expresa el contenido sustancial del deber de debida diligencia:

"7. Los Estados Partes condenan todas las formas de violencia contra la mujer y convienen en adoptar, por todos los medios apropiados y sin dilaciones, políticas orientadas a prevenir, sancionar y erradicar dicha violencia y en llevar a cabo lo siguiente:

$\cdots$

b. Actuar con la debida diligencia para prevenir, investigar y sancionar la violencia contra la mujer".

En un sentido similar pero incluso más amplio, la Recomendación General 19 del Comité de la CEDAW sobre "la violencia contra la mujer", señala que:

"9. ... de conformidad con la Convención, la discriminación no se limita a los actos cometidos por los gobiernos o en su nombre (véanse los incisos e) y f) del artículo 2 y el artículo 5). Por ejemplo, en virtud del inciso e) del artículo 2 de la Convención, los Estados Partes se comprometen a adoptar todas las medidas apropiadas para eliminar la discriminación contra la mujer practicada por cualesquiera personas, organizaciones o empresas. En virtud del derecho internacional y de pactos específicos de derechos humanos, los Estados también pueden ser responsables de actos privados si no adoptan medidas con la diligencia debida para impedir la violación de los derechos o para investigar y castigar los actos de violencia e indemnizar a las víctimas" ${ }^{\prime 58}$.

Como se advirtió anteriormente, el presente escrito tiene como objeto de análisis específico la obligación de prevención del Estado. Sobre este punto, de la mano con los avances de la Corte Europea ${ }^{59}$, la COIDH ha desarrollado una postura clara y uniforme en relación con el deber de prevención del Estado en relación con los actos de terceros.

\footnotetext{
${ }^{58}$ Comité para la Eliminación de la Discriminación contra la Mujer, cit. nota n. 19, párr. 9.

${ }^{59}$ Conforme a la jurisprudencia más reconocida de la Corte Europea, para que surja el deber positivo de prevención en cabeza del Estado por el acto de terceros, "debe ser establecido que al momento de los hechos las autoridades sabían, o debían haber sabido, de la existencia de un riesgo real o inmediato para la vida de un individuo identificado o de algunos individuos respecto de actos criminales de terceros, y que tales autoridades no tomaron las medidas dentro del alcance de sus poderes que, juzgadas razonablemente, podían esperarse para evitar dicho riesgo". Véase: Osman con Reino Unido, Corte Europea de Derechos Humanos, Deber de prevención, 28 de octubre de 1998, Demanda № 23452/94., párr. 115. En: http://www.bailii.org/eu/cases/ECHR/1998/101.html [visitado el 24/11/2010]; Kilic con Turquía, Corte Europea de Derechos Humanos, Responsabilidad estatal por violencia de género, 28 de marzo de 2000, Demanda № 22492/93, párrafos. 62-63. En: http://www.humanrights.is/the-humanrights-project/humanrightscasesandmaterials/cases/regionalcases/europeancourtofhumanrights/nr/547 [visitado el 24/11/2010].
} 
Al respecto, la COIDH ha señalado que el Estado no puede ser responsabilizado de manera ilimitada por todos los actos que cometan particulares dentro de su jurisdicción ${ }^{60}$. Asimismo, y como una herramienta que aporta a la seguridad jurídica en el sistema, la COIDH ha establecido un test tripartito para la determinación de la responsabilidad internacional por violación al deber de prevención: (i) en primer lugar, el Estado deberá tener un conocimiento de una situación de riesgo real e inmediato; (ii) en segundo lugar, que ese riesgo verse sobre un individuo o grupo de individuos determinados o determinables, y (iii) en tercer lugar, se precisa verificar posibilidades razonables de prevenir o evitar ese riesgo ${ }^{61}$.

No obstante lo anterior, las dinámicas de violaciones de derechos humanos entre terceros no pierden su complejidad y desde la perspectiva del Estado, las exigencias absolutas de prevención son ilegítimas e imprácticas. De esta forma, conviene adentrarse en las soluciones que, de manera particular, la $\mathrm{COIDH}$ ha ofrecido para delimitar el alcance del deber de prevención del Estado en relación con los actos privados de violencia contra la mujer.

\section{La denuncia como fuente}

de conocimiento y limitante al deber de prevención: el caso Campo Algodonero y María da Penha Maia Fernández

Con ocasión de su decisión en el caso conocido como Campo Algodonero, la COIDH tuvo la oportunidad de referirse sobre un supuesto incumplimiento de la obligación de garantía por parte del Estado mexicano, respecto del derecho a la vida de las tres mujeres fallecidas. Lo anterior, en el marco del riesgo generalizado que representaba Ciudad Juárez para la fecha de los hechos ${ }^{62}$, y el

\footnotetext{
${ }^{60}$ Masacre de Pueblo Bello con Colombia, Corte Interamericana de Derechos Humanos, Masacre y secuestros realizados por una organización paramilitar en el corregimiento de Pueblo Bello, 31 de enero de 2006, Serie C No 140, 2006, párr. 123. En: http://www.corteidh.or.cr/docs/casos/Artículos/ seriec_140_esp. doc [visitado el 16/07/2013].

${ }^{61}$ Comunidad Indígena Sawhoyamaxa con Paraguay, Corte Interamericana de Derechos Humanos, Responsabilidad internacional del Estado por no haber garantizado el derecho de propiedad ancestral de la Comunidad Sawhoyamaxa, Sentencia de 29 de marzo de 2006, Serie C No 146, 2006, párr. 155. En: http://www.corteidh.or.cr/tablas/fichas/indigena_sawhoyamaxa.pdf [visitado el 16/07/2013]; Valle Jaramillo y otros con Colombia, Corte Interamericana de Derechos Humanos, Responsabilidad internacional del Estado por la ejecución extrajudicial de Jesús Valle Jaramillo, 27 de noviembre de 2008, Serie C No 192, 2008, párr. 78. En: http://www.corteidh.or.cr/tablas/fichas/vallejaramillo.pdf [visitado el 16/07/2013]. Adicionalmente, véase: Perozo y otros con Venezuela, Corte Interamericana de Derechos Humanos, Responsabilidad internacional del Estado por las restricciones a la libertad de expresión en perjuicio de 44 personas vinculadas al canal de televisión Globovisión, cit. nota n. 13, párr. 121. En: http://www.corteidh.or.cr/tablas/fichas/perozo.pdf [visitado el 16/07/2013], y Ríos y otros con Venezuela, Corte Interamericana de Derechos Humanos, cit. nota n. 12, párr. 110.

${ }^{62}$ González y otras ("Campo Algodonero") con México, Corte Interamericana de Derechos Humanos, cit. nota n. 10, párr. 144.
} 
cual afectaba de forma desproporcionada a las mujeres ${ }^{63}$. En este punto, aunque la COIDH no contaba con cifras concretas o confiables sobre el número real de mujeres afectadas en su vida e integridad, la misma concluyó que, en todo caso, las mismas eran lo suficientemente alarmantes ${ }^{64} \mathrm{e}$ ilustrativas sobre la existencia de un patrón de violencia generalizado por razones de género ${ }^{65}$.

En particular, la COIDH pudo evidenciar cómo la industria maquiladora presente en la zona había transformado el rol de la mujer, haciéndola más competitiva y suministrándole un nuevo rol como proveedora del hogar. Según informes del propio Comité de la CEDAW, esta situación guardaba relación con el incremento de la violencia como forma de retaliación masculina ${ }^{66}$.

Bajo este escenario y contexto, la COIDH señaló que en relación con la situación de las víctimas antes de su desaparición, no se le podía imputar al Estado un deber de prevención ilimitado ${ }^{67}$. La COIDH destacó que el factor detonante del deber de prevención era la demostración del conocimiento sobre la existencia de un riesgo real o inmediato para las víctimas ${ }^{68}$.

Ahora bien, en relación con la situación de las víctimas antes del descubrimiento de sus cuerpos, pero después de los reportes de su desaparición, la COIDH señaló que, dado el contexto del caso, el Estado debía tener conocimiento del riesgo real e inmediato que enfrentaban las víctimas. Según la Corte:

"[...] ante tal contexto surge un deber de debida diligencia estricta frente a denuncias de desaparición de mujeres, respecto a su búsqueda durante las primeras horas y los primeros días $[\ldots]^{\prime \prime 69}$.

A la luz de lo anterior, consideramos que la denuncia surge como el factor que determina la concreción de los deberes de prevención del Estado, de tal

${ }^{63}$ Comisión Interamericana de Derechos Humanos, Situación de los Derechos de la Mujer en Ciudad Juárez, México: El Derecho a No Ser Objeto de Violencia y Discriminación, 2003. En: http://www. cidh.org/annualrep/2002sp/cap. vi.juarez.htm [visitado el 16/07/2013].

${ }^{64}$ González y otras ("Campo Algodonero") con México, Corte Interamericana de Derechos Humanos, cit. nota n. 10, párr. 121.

${ }^{65}$ González y otras ("Campo Algodonero") con México, Corte Interamericana de Derechos Humanos, cit. nota n. 10, párr. 127 y 164.

${ }^{66}$ González y otras ("Campo Algodonero") con México, Corte Interamericana de Derechos Humanos, cit. nota n. 10, párr. 132 y 133.

${ }^{67}$ La Corte divide su estudio del deber de investigación en dos momentos claves: el primero, antes de la desaparición de las víctimas; y el segundo, antes de la localización de sus cuerpos sin vida. (González y otras ("Campo algodonero") con México, Corte Interamericana de Derechos Humanos, Violencia de género, 16 de noviembre de 2009, Casos número: 12.496, 12.497 y 12.498, 2009, párr. 281).

${ }^{68}$ González y otras ("Campo Algodonero") con México, Corte Interamericana de Derechos Humanos, cit. nota n. 10, párr. 282.

${ }^{69}$ González y otras ("Campo Algodonero") con México, Corte Interamericana de Derechos Humanos, cit. nota n. 10, párr. 283. 
manera que permite exigirle una actuación particular de protección como medida de prevención. A su turno, la presencia de un contexto de violencia contra la mujer previo no pasa desapercibido y, por el contrario, constituye el fundamento para predicar la existencia de obligaciones reforzadas de prevención.

Sobre este último aspecto se pronunció la $\mathrm{CIDH}$ en el caso de la señora María da Penha. Este caso describe un escenario en donde, por más de 15 años, el Estado de Brasil conoció de actos de violencia intrafamiliar en contra de la señora María da Penha. Al momento de la presentación de la denuncia ante la CIDH en 1998, María da Penha sufría de paraplejía irreversible a causa de las golpizas propinadas por su marido.

Dentro del análisis de la situación, la CIDH verificó que la situación de la víctima se inscribía en un contexto discriminatorio de tolerancia respecto de la violencia doméstica, razón por la cual, pese a la existencia de comisarías especializadas, las denuncias y quejas no eran debidamente investigadas ni tramitadas. Esta situación había propiciado, entre otros fenómenos, que las mujeres perdieran confianza en el sistema $y$, por lo tanto, dejaran de denunciar ${ }^{70}$. Adicionalmente, los funcionarios de las comisarías no se encontraban capacitados ni sensibilizados, generando que los procesos de entrevistas y testimonios se tornaran vergonzosos y humillantes para las víctimas.

Finalmente, aunque se habían iniciado medidas en el campo legislativo como respuesta estatal a la violencia doméstica, la $\mathrm{CIDH}$ puso de presente que el proceso de implementación había sido lento y que, en todo caso, no había tenido ningún efecto en la situación de María da Penha ${ }^{71}$. Según la $\mathrm{CIDH}$, la ineficacia judicial, la impunidad y la imposibilidad de la víctima de obtener reparación, constituyen una muestra de la falta de compromiso para reaccionar adecuadamente frente a la violencia doméstica ${ }^{72}$.

La CIDH señaló de manera severa que:

“56. Dado que esta violación contra María da Penha forma parte de un patrón general de negligencia y falta de efectividad del Estado para procesar y condenar a los agresores, considera la Comisión que no sólo se viola la obligación de procesar y condenar, sino también la de prevenir estas prácticas degradantes. Esa inefectividad judicial general y discriminatoria crea el ambiente que facilita la violencia doméstica, al no existir eviden-

\footnotetext{
${ }^{70}$ Comisión Interamericana de Derechos Humanos, Informe sobre la Situación de los Derechos Humanos en Brasil, 1997. En: http://www.cidh.oas.org/countryrep/Brasesp97/indice.htm [visitado el 16/07/2013].

${ }^{71}$ Comisión Interamericana de Derechos Humanos, Informe № 54/01, 2001, párr. 49-50. En: http:// www.cidh.oas.org/annualrep/2000sp/capituloiii/fondo/brasil12.051.htm [visitado el 16/07/2013].

${ }^{72}$ Comisión Interamericana de Derechos Humanos, cit. nota n. 71, párr. 57.
} 
cias socialmente percibidas de la voluntad y efectividad del Estado como representante de la sociedad, para sancionar esos actos" ${ }^{\prime \prime 3}$.

La CIDH valoró la falta de condena del esposo de María da Penha como una violación a la obligación, conforme a la $C B D P$, de proveer recursos efectivos para la sanción de la violencia contra la mujer. Asimismo, consideró que este comportamiento constituía un acto de tolerancia por parte del Estado a la violencia de la que fue víctima esta mujer por 15 años. La CIDH concluyó que esta conducta de los órganos judiciales brasileros no era exclusiva de este caso, sino parte de una pauta sistemática ${ }^{74}$.

2. Obligación positiva de consagrar normativamente garantías de protección como parte del deber de prevención: Caso A.T. con Hungría del Comité de la CEDAW

La tipificación del delito de violencia intrafamiliar no puede valorarse como una medida suficiente para combatir la violencia contra la mujer. De manera necesaria, se requieren mecanismos legislativos y administrativos que complementen la sanción en abstracto de la violencia contra la mujer y le permitan protegerse frente a futuras agresiones. Sin embargo, por tratarse de una solución jurisdiccional urgente, sólo serán satisfactorias aquellas acciones estatales que, con una fuerte probabilidad y no en mera apariencia, atiendan el planteo formulado por la víctima ${ }^{75}$.

La importancia de los anteriores razonamientos quedó evidenciada en el caso de la señora A.T. con Hungría, ante el Comité de la CEDAW.

El 10 de octubre de 2003, el Comité de la CEDAW conoció de una comunicación elevada por la señora A.T. de nacionalidad húngara, quien alegaba ser víctima de violaciones por parte del Estado de Hungría frente a las obligaciones positivas de protección en relación con su vida e integridad personal ${ }^{76}$. En particular, la autora señaló que el Estado había descuidado sus obligaciones positivas al omitir otorgarle medidas de protección contra las agresiones y amenazas de su antiguo concubino; situación que se manifestó en la perpetuación y agravación de las instancias de violencia contra ella ${ }^{77}$.

\footnotetext{
${ }^{73}$ Comisión Interamericana de Derechos Humanos, cit. nota n. 71, párr. 56.

${ }^{74}$ Comisión Interamericana de Derechos Humanos, cit. nota n. 71, párr. 55.

${ }^{75}$ Organización Panamericana de la Salud, Modelo de leyes y políticas sobre violencia intrafamiliar contra las mujeres, 2004, p. 20. En: http://www1.paho.org/Spanish/AD/GE/LeyModelo.pdf [visitado el 16/07/2013].

${ }^{76}$ Comité para la Eliminación de la Discriminación contra la Mujer, cit. nota n. 16, párr. 3.1.

${ }^{77}$ Comité para la Eliminación de la Discriminación contra la Mujer, cit. nota n. 16.
} 
La señora A.T. puso en conocimiento del Comité que durante cuatro años había sido víctima de violencia doméstica y de graves amenazas por parte de su antiguo esposo y padre de sus hijos. En uno de los eventos, la peticionaria sufrió una lesión cerebral grave. Adicionalmente, la autora señaló que aunque su antiguo esposo abandonó el domicilio familiar, seguía frecuentando el lugar, propinándole graves palizas, las cuales se encontraban documentadas en reportes médicos. Aunque los hechos eran plenamente conocidos por las autoridades húngaras, nunca se encarceló a su agresor ni se tomaron medidas de protección ya que, en la legislación húngara, no se preveían órdenes de protección ni interdictos y no existían albergues debidamente equipados para admitir a un niño totalmente discapacitado junto con su madre y hermana ${ }^{78}$. Asimismo, cuando la autora intentó solicitar medidas de carácter civil para restringir el acceso del ex concubino al domicilio familiar, las cortes internas de Budapest privilegiaron el derecho conjunto del agresor a la propiedad ${ }^{79}$.

$\mathrm{Al}$ respecto, es importante resaltar que el Comité de la CEDAW ya había señalado en sus observaciones finales del año 2002 que en Hungría existía un contexto prevalente de violencia contra la mujer y las niñas, incluida la violencia doméstica. De igual forma, había manifestado su preocupación por la falta de legislación específica en materia de violencia doméstica y acoso sexual, "la inexistencia de órdenes judiciales de amparo o de abandono del hogar, o de albergues para la protección inmediata de las mujeres víctimas de violencia doméstica" ${ }^{80}$. Adicionalmente, había expresado su "preocupación por la persistencia de estereotipos tradicionales arraigados, en relación con las funciones y las responsabilidades de mujeres y hombres en el marco de la familia ${ }^{\prime \prime 1}$.

En el caso en concreto, el Comité de la CEDAW fundamentó su decisión final de condena en contra de Hungría, en la constatación del conocimiento por parte de las autoridades acerca de la prolongación de la violencia contra la señora A.T. sin que a favor de la misma se otorgara alguna medida eficaz de protección. Asimismo, en la inexistencia de disposiciones legales para hacer efectiva una orden de restricción y en la carencia de infraestructura administrativa que permitiera buscar un albergue adecuado para ella y sus hijos ${ }^{82}$.

\footnotetext{
${ }^{78}$ Comité para la Eliminación de la Discriminación contra la Mujer, cit. nota n. 16, párr. 2.1.

${ }^{79}$ Comité para la Eliminación de la Discriminación contra la Mujer, cit. nota n. 16, párr. 2.4.

${ }^{80}$ Comité para la Eliminación de la Discriminación contra la Mujer, Observaciones finales del Comité - CEDAW: Hungría. 23/08/2002. A/57/38, párr. 301-338. (Concluding Observations/Comments), 2002, párr. 321. En: http://www.acnur.org/biblioteca/pdf/5359.pdf?view=1 [visitado el 16/07/2013].

${ }^{81}$ Comité para la Eliminación de la Discriminación contra la Mujer, cit. nota n. 80, párr. 319.

${ }^{82}$ Comité para la Eliminación de la Discriminación contra la Mujer, cit. nota n. 16, párr. 9.4.
} 


\section{De la obligación de seguimiento en los casos de violencia doméstica como garantía adicional de prevención: Caso Sahide Goecke (fallecida) con Austria y Fatma Yildirim (Fallecida) con Austria del Comité de la CEDAW}

Aunque el caso A.T. con Hungría resulta ilustrativo acerca de la necesidad de establecer mecanismos legales y administrativos de protección de la mujer contra la violencia, lo cierto es que las medidas de prevención (cauciones, órdenes de desalojo del domicilio familiar, etc.) pueden resultar ineficaces cuando las mismas no se encuentran acompañadas del seguimiento respectivo por parte de las autoridades competentes.

Al efecto, piénsese en un caso tan factible como el de un agresor que desatiende la orden dictada por un juez y vuelve al domicilio para tomar represalias contra la mujer que lo denunció. En este caso, las prohibiciones previamente dictadas en sede administrativa o judicial serán insuficientes si las autoridades encargadas no velan por la efectiva aplicación de las mismas.

La importancia del deber de seguimiento quedó evidenciada en el caso de la señora Sahide Goecke con Austria ${ }^{83}$.

En este caso, la señora Sahide Goecke fue víctima de fuertes atentados contra su integridad personal y su vida durante un periodo de 3 años. Los actos de violencia incluyeron estrangulamientos repetidos y constantes amenazas de muerte. La víctima de este caso acudió en numerosas ocasiones ante las autoridades de policía, quienes ordenaron diversas medidas, entre las cuales se incluyeron órdenes de expulsión, prohibiciones de regreso y solicitudes de detención contra su agresor $^{84}$. Sin embargo, en todos los casos, y a pesar de la gravedad de las lesiones, el Fiscal denegó las peticiones de privación de libertad. Asimismo, en varias oportunidades, el padre de la víctima se comunicó con las autoridades señalando que el agresor había vuelto a amenazar a su hija y que incluso había comprado un arma. Lo anterior, pese a una prohibición vigente de tenencia en su contra. Finalmente, el enjuiciamiento por lesiones corporales y amenazas peligrosas punibles fue suspendido por falta de pruebas. Dos días después, la policía fue nuevamente advertida sobre una pelea entre la señora Goecke y su agresor, no obstante, ningún agente estatal acudió al domicilio en el que horas después sería asesinada la señora Sahide Goecke frente a sus dos hijos ${ }^{85}$.

\footnotetext{
${ }^{83}$ Comité para la Eliminación de la Discriminación contra la Mujer, Comunicación № 5/2005, Sahide Goekce contra Austria, 2007. En: http://www.equidad.scjn.gob.mx/IMG/pdf/Caso_Sahide_Goekce_fallecida_v-_Austria.pdf [visitado el 14/07/2013].

${ }^{84}$ Comité para la Eliminación de la Discriminación contra la Mujer, cit. nota n. 83, párr. 2.4, 2.5 y 2.6.

${ }^{85}$ Comité para la Eliminación de la Discriminación contra la Mujer, cit. nota n. 83, párr. 2.10, 2.11, 2.12 .
} 
En su decisión del caso, el Comité de la CEDAW señaló que la existencia de un modelo amplio para hacer frente a la violencia doméstica, incluyendo la existencia de legislación, recursos penales y civiles, centros de acogida, asesoramiento para víctimas, etc., resultan insuficientes cuando no se cuenta "con el apoyo de agentes estatales que respeten las obligaciones de diligencia debida del Estado Parte" ${ }^{\prime 66}$. El Comité señaló que conforme a la combinación de factores en el presente caso, la policía sabía o debía haber sabido del grave peligro que corría Sahide Goecke y debió valorar su última Ilamada, como una advertencia de emergencia que requería acción inmediata ${ }^{87}$.

Un caso similar tuvo lugar en contra de la señora Fatma Yildirim ${ }^{88}$, quien fue amenazada de muerte en numerosas ocasiones por parte de su antiguo esposo, situaciones que fueron reportadas a las autoridades policiales de Austria. En una oportunidad, las denuncias y solicitudes de protección fueron realizadas por un centro especializado de protección a la mujer contra la violencia doméstica, el cual solicitó que adicionalmente se prestara mayor atención al caso de la señora Yildirim. Las solicitudes de detención fueron rechazadas en numerosas oportunidades por la Fiscalía. Ahora bien, como consecuencia de una demanda de divorcio, se concedió una medida cautelar en contra del esposo agresor en la cual se le prohibía todo tipo de acercamiento ${ }^{89}$. No obstante, el 11 de septiembre de 2003, diez días después de emitidas las ordenes de protección, Fatma Yildrim fue asesinada por su esposo mientras regresaba a su casa después de trabajar ${ }^{90}$.

En su decisión sobre el caso, el Comité de la CEDAW emitió varios pronunciamientos que resultan importantes a la hora de entender el alcance del deber de prevención del Estado en los casos de violencia contra la mujer:

a) La legislación, recursos penales y civiles, la capacitación, centros de acogida y el asesoramiento a las víctimas de violencia, no son suficientes para que una mujer víctima de violencia doméstica pueda gozar de la realización práctica del principio de igualdad. Por el contrario, es necesario "recibir el apoyo de los agentes estatales que se adhieran a las obligaciones del Estado Parte de proceder con la debida diligencia" ${ }^{\prime 11}$.

\footnotetext{
${ }^{86}$ Comité para la Eliminación de la Discriminación contra la Mujer, cit. nota n. 83, párr.12.1.2.

${ }^{87}$ Comité para la Eliminación de la Discriminación contra la Mujer, cit. nota n. 83, párr. 12.1.4.

${ }^{88}$ Comité para la Eliminación de la Discriminación contra la Mujer, Comunicación № 6/2005, Fatma Yildirim contra Austria, 2007. En http://www.equidad.scjn.gob.mx/IMG/pdf/Caso_Fatma_Yildirim_fallecida_v-_Austria.pdf [visitado el 14/07/2013].

${ }^{89}$ Comité para la Eliminación de la Discriminación contra la Mujer, cit. nota n. 88, párr. 2.7, 2.8, 2.9, $2.10,2.11,2.12$.

${ }^{90}$ Comité para la Eliminación de la Discriminación contra la Mujer, cit. nota n. 88, párr. 2.13.

${ }^{91}$ Comité para la Eliminación de la Discriminación contra la Mujer, cit. nota n. 88, párr. 12.1.2.
} 
b) Las medidas positivas adoptadas por la víctima son relevantes a la hora de determinar la responsabilidad del Estado, pues constituyen el medio de comunicación idóneo para que el mismo se entere de la entidad del riesgo ${ }^{92}$.

c) Cuando los hechos del caso revelan una situación extremadamente peligrosa de la que las autoridades tienen conocimiento (como en el caso de Fatma Yildrim), no es admisible que la Fiscalía decida negar los pedidos de la policía de arrestar al agresor y ubicarlo en un lugar de detención. Se deben evaluar todos los factores que puedan influir en la peligrosidad del agente privado $^{93}$.

\section{LA OBLIGACIÓN DE PERSECUCIÓN DEL DELITO DE}

VIOLENCIA INTRAFAMILIAR Y EL RESPETO POR LA VIDA PRIVADA DE LA MUJER

En relación con la obligación de persecución de la violencia contra la mujer, un Estado puede optar por cumplir con sus obligaciones derivadas del artículo 7.b de la $C B D P$, caracterizando el delito de violencia intrafamiliar como un delito perseguible de oficio. En este caso, el Estado investigará y sancionará de manera irrestricta todos los hechos de violencia contra la mujer generados en el ámbito intrafamiliar. Esta posición sería, en inicio, plenamente acorde con el sistema interamericano y universal de protección de los derechos humanos.

Sin embargo, esta posición podría ser valorada igualmente, como una intromisión indebida en la vida privada de la mujer y, en particular, como una violación a su derecho legítimo de decidir continuar su vida familiar con la persona que ama, a pesar de los hechos de violencia. En este punto, cabe señalar que, en el marco del sistema europeo de protección de los derechos humanos, el respeto por la vida privada al interior de la familia se ha entendido en función del respeto por las decisiones individuales en lo que a la forma de vivir la vida propia se refiere ${ }^{94}$. Con gran precisión, la Corte Europea de Derechos Humanos ha señalado que "los ataques o restricciones en la persona de un individuo dan lugar a violaciones del artículo 8 (derecho a la vida familiar y privada), en la medida en que afectan su integridad personal/95. Consciente de

\footnotetext{
${ }^{92}$ Comité para la Eliminación de la Discriminación contra la Mujer, cit. nota n. 88, párr. 12.1.3.

${ }^{93}$ Comité para la Eliminación de la Discriminación contra la Mujer, cit. nota n. 88, párr. 12.1.4.

${ }^{94}$ JanIS, Mark Warren; KaY, Richard S.; Bradley, Anthony Wilfred, European Human Rights Law: Text and Materials, Oxford University Press, Oxford, 2008, p. 373. En: http://books.google.com.co/books? id=T69A2ToYrOMC\&printsec $=$ frontcover\&hl=es\&source=gbs_ge_summary_r\&cad $=0 \# v=$ onepage \&q $\& \mathrm{f}=$ false [visitado el 16/07/2013].

${ }^{95} \mathrm{X}$ e Y con Países Bajos, Corte Europea de Derechos Humanos, Violación sexual de una adolescente con discapacidad mental como una violación a los derechos humanos, 26 de marzo de 1998, Serie A No 91, 1985. En: http://www.juridischeuitspraken.nl/19850326EHRMXenYtegenNederland.pdf [visitado el 15/09/2010].
} 
estas obligaciones, el Estado puede decidir beneficiar entonces, la integridad personal de la mujer y tipificar el delito de violencia intrafamiliar como querellable. En este escenario, y como consecuencia inmediata de dicho carácter, el sujeto pasivo del delito será el único legitimado para iniciar la acción penal y, habiendo decidido iniciarla, podrá desistir o retractarse de la querella en cualquier momento ${ }^{96}$. Bajo este contexto, la $\mathrm{CIDH}$ ha criticado la promoción de la conciliación como método para resolver delitos de violencia intrafamiliar contra las mujeres ${ }^{97}$. De igual manera, ha instado a los diferentes Estados para que no le asignen un valor probatorio descontextualizado a la retractación de la denuncia por parte de las mujeres y a entender que, situaciones como la estigmatización por parte de la sociedad ${ }^{98}$; la dependencia económica con respecto al cónyuge agresor; y el temor a las represalias, son motivos comprobados para que la mujer desista de su reclamación pena ${ }^{99}$.

Sumado a lo anterior, la ausencia de funcionarios judiciales y administrativos sensibilizados en la violencia de género, se ha erigido como una falencia histórica de los sistemas de administración de justicia latinoamericanos, que ha exacerbado las instancias de impunidad en el continente ${ }^{100}$.

\section{Las soluciones planteadas a la luz del caso Nahide Opuz con Turquía: equilibrio entre el respeto por la vida privada y libre albedrío de la mujer y las obligaciones de protección del Estado}

El problema jurídico sub examine fue sometido a la consideración de la $\mathrm{CEDH}$, en el caso de la señora Nahide Opuz con Turquía ${ }^{101}$. Este caso presentó un cuadro general y continuado de violencia en contra de la señora Opuz y, posteriormente, en contra de su madre.

Aunque en el caso en comento los procedimientos penales se iniciaban con cada denuncia, las investigaciones cesaban tan pronto la misma era re-

\footnotetext{
${ }^{96}$ Gimbernat Ordeig, Enrique, Sobre algunos aspectos del delito de violación en el Código Penal español: con especial referencia a la violación intimidatoria, Tecnos, Madrid, 1990, p. 90.

${ }^{97}$ Comisión Interamericana de Derechos Humanos, cit. nota n. 45, párr. 210.

${ }^{98}$ Comisión Interamericana de Derechos Humanos, Informe No 5/96, 1996, p. 15. En: http://www. demus.org.pe/publicacion/09f_seriejg_avances_en_el_sistema.pdf [visitado el 16/07/2013].

${ }_{99}$ Comisión Interamericana de Derechos Humanos, cit. nota n. 45, párr. 209-210.

${ }^{100}$ Comisión Interamericana de Derechos Humanos, cit. nota n. 70.

${ }^{101}$ Opuz con Turquía, Corte Europea de Derechos Humanos, Violencia doméstica como una violación a los derechos humanos y una forma de discriminación, 9 de junio de 2009, Demanda № 33401/02, 2009. En: http://www.equidad.scjn.gob.mx/IMG/pdf/Caso_Opuz_c-_Turquia.pdf [visitado el 16/07/2013]. Más recientemente: A. con Croacia, Corte Europea de Derechos Humanos, Violencia doméstica, 14 de octubre de 2010. Solicitud No 55164/08.
} 
tirada. En estas circunstancias, el tribunal europeo se vio en la necesidad de determinar si, como parte del deber de prevención del Estado, y conforme al derecho internacional consuetudinario reflejado en las legislaciones domésticas europeas, existía una obligación de persecución después del retiro de la denuncia ${ }^{102}$.

En su decisión final, la Corte estableció que no existía un consenso general que obligue al Estado a continuar con el proceso penal por el delito de violencia intrafamiliar cuando la víctima ha retirado la denuncia ${ }^{103}$. Sin embargo, en sentido conciliador con los derechos en pugna, el tribunal europeo señaló que dicho retiro no podía ser entendido como una liberación absoluta de las cargas u obligaciones del Estado. En particular, la Corte se refirió a la necesidad de evaluar las siguientes circunstancias, con miras a decidir si acusar o no, a pesar del retiro de la denuncia:

"-la gravedad del delito - si los daños de la víctima son físicos o psicológicos - si el acusado usó un arma - si el acusado realizó alguna amenaza desde el ataque - si el acusado había planificado el ataque - el efecto que pudo haber tenido en cualquier niño que viviera en el hogar - la probabilidad de que el acusado vuelva a delinquir - si el retiro de la denuncia obedece a amenazas - la amenaza constante a la salud y la seguridad de la víctima o de cualquier otra persona que estuviera, o pudiera estar involucrada - el estado actual de la relación de la víctima con el acusado - el efecto que tuvo continuar con la acusación en contra de los deseos de la víctima en su relación con el acusado - la historia de la relación, en especial si había habido otras instancias de violencia en el pasado"104.

A la luz de los anteriores criterios, la Corte emitió un pronunciamiento que, a nuestro parecer, le permite al Estado resolver una disyuntiva, inicialmente insalvable, a favor de los derechos humanos de todas las personas bajo su jurisdicción. Según este Tribunal, a pesar de que no exista un consenso universal en relación con la actuación subsiguiente al retiro de la denuncia, mientras más grave sea el delito y más grande la probabilidad de que se cometan unos nuevos, más exigible la obligación de continuar el procesamiento del acusado en nombre del interés público ${ }^{105}$.

Asimismo, entendió la Corte que el respeto por la vida familiar no puede ser un argumento válido para interrumpir la acción penal por causa del retiro de la denuncia en aquellas instancias en que sea posible establecer que la violencia ha estado presente desde los inicios de la relación; que la misma ha sido pla-

\footnotetext{
102 Opuz con Turquía, Corte Europea de Derechos Humanos, cit. nota n. 101, párr. 131.

${ }^{103}$ Opuz con Turquía, Corte Europea de Derechos Humanos, cit. nota n. 101, párr. 87, 88, 89.

${ }^{104}$ Opuz con Turquía, Corte Europea de Derechos Humanos, cit. nota n. 101, párr. 138.

${ }^{105}$ Opuz con Turquía, Corte Europea de Derechos Humanos, cit. nota n. 101, párr. 139.
} 
nificada; y que se ha recurrido al uso de armas letales. Bajo este marco fáctico, el aumento de la violencia no sólo es posible sino predecible ${ }^{106}$.

\section{CONCLUSIOnES}

Durante las últimas décadas, los diferentes sistemas de protección de los derechos humanos han virado hacia una marcada tendencia de garantía y protección en lo que a las víctimas de la violencia de género concierne. En ese sentido, los sistemas interamericano, europeo y universal, a través de sus órganos competentes, han adoptado jurisprudencialmente una sustentada perspectiva de género que persigue erradicar todos aquellos actos que, de manera visible o invisible, han relegado y/o limitado a la mujer en el ejercicio pleno de sus derechos. En este contexto, la interpretación de los distintos órganos supra nacionales ha avanzado en lo que respecta a la exigencia de obligaciones más estrictas para los Estados, quienes no pueden excusarse en el cumplimiento de la mera obligación de respeto, sino que además se erigen como titulares de obligaciones positivas, que para la situación específica se traducen en el deber de prevención, e incluso, en el de seguimiento.

La violencia de género, aunque puede adoptar diferentes perspectivas, puede definirse en consenso, de conformidad con lo expuesto por la jurisprudencia de la Corte Interamericana de Derechos Humanos, como todo acto violatorio de los derechos humanos de la mujer, que se dirige especialmente hacia ella por el hecho de serlo, o que la afecta de manera desproporcionada. Así, es imperativo señalar que la violencia intrafamiliar constituye una de sus múltiples manifestaciones. Sin embargo, en este punto resulta pertinente aclarar que, como se expuso, no es posible catalogar todo acto de violencia indiscriminada que de alguna u otra forma afecte a la mujer como violencia de género, pues en este caso no existe algún tipo de consideración diferenciada.

De igual manera, no es posible confundir el género con el sexo, pues la noción de género es mucho más compleja: el género es conformado socialmente y se refiere al modo de ser hombre o mujer en una cultura determinada, a sus roles y atribuciones sociales.

Ahora bien, ante un panorama desolador de violencia de género en las Américas, la Convención Belém do Pará surge en el sistema interamericano, como una herramienta idónea que garantiza y salvaguarda los derechos de las mujeres, a través del establecimiento de obligaciones precisas para los Estados, especialmente en lo que respecta a la prevención, sanción y erradicación de la violencia contra la mujer. Si bien, en principio, se tornaba dudosa la justiciabilidad de este instrumento, específicamente de su artículo $7^{\circ}$, la Corte

${ }^{106}$ Opuz con Turquía, Corte Europea de Derechos Humanos, cit. nota n. 101, párr. 140, 141. 
Interamericana, a partir del caso de Campo Algodonero en contra de México, estructuró un andamiaje jurídico que le permitió declarar la plena justiciabilidad de la disposición referida.

Así, en estos momentos, las obligaciones positivas de los Estados frente a este tipo de situaciones se encuentran totalmente vigentes. No obstante, en lo que al deber de prevención respecta, tanto la Corte Interamericana como la Corte Europea de Derechos Humanos han señalado que la denuncia o la medida adoptada por la víctima frente el Estado puede constituir el factor determinante de responsabilidad estatal, pues se consolida como el medio de comunicación idóneo para que él mismo se entere de la entidad del riesgo.

Finalmente, la imputación de una obligación de seguimiento al Estado en el marco de su deber de garantía y prevención frente a una situación de violencia de género intrafamiliar, resulta, en principio, un mecanismo plenamente acorde a las exigencias requeridas por los instrumentos de protección en los diferentes sistemas regionales y en el universal. No obstante, los seguimientos oficiosos de las investigaciones, más allá del retiro de la denuncia, pueden observarse como una intromisión indebida en la vida privada de la mujer y, en particular, como una violación de su derecho legítimo a decidir continuar su vida familiar con la persona que ama, a pesar de los hechos de violencia. En este desconcertante contexto de colisión, la Corte Europea de Derechos Humanos establece un importante precedente al determinar como parte del deber de prevención del Estado, la obligación de persecución después del retiro de la denuncia, pues esta retractación puede estar viciada por el miedo o la situación de indefensión que, en la mayoría de estos casos, enfrenta la mujer en el seno de su hogar. De esta manera, en sentido conciliador, este Tribunal afirmó que dicho retiro no podía ser entendido como una liberación absoluta de las cargas obligaciones del Estado, pues atendiendo a diversas circunstancias, el Estado conocedor del riesgo debe adoptar la conducta que razonablemente se espera.

\section{BiBLIOGRAFÍA CITADA}

\section{Artículos de publicaciones periódicas}

Bustamante Arango, Diana Marcela y Vásquez Henao, Paola Andrea, "La Convención Belém Do Pará un balance de su aplicación en la jurisprudencia de la Corte Interamericana, a 16 años de su entrada en vigor", Civilizar Ciencias Sociales y Humanas, volumen 11, número 20, 2011, pp. 1536. En: http://www.usergioarboleda.edu.co/civilizar/civilizar-20/LA\%20 CONVENCI\%C3\%93N\%20BEL\%C3\%89M.pdf [visitado el 22/12/2011].

BYRNES, Andrew y BATH, Eleanor, "Violence against Women, the Obligation of Due Diligence, and the Optional Protocol to the Convention on the Elimination of All Forms of Discrimination against Women-Recent Developments", 
Human Rights Law Review, volumen 8, número 3, 2008, pp. 517-533. En: http://www.deepdyve.com/lp/ou-press/violence-against-women-theobligation-of-due-diligence-and-the-0vGmfxfE0o?shortRental=true [visitado el 13/07/2013].

Dragiewicz, Molly y Lindgreen, Yvonne, "The gendered nature of domestic violence: statistical data for lawyers considering equal protection analysis", Journal of Gender, Social Policy \& the Law, volumen 17, número 2, 2009, p. 231. En: http://xa.yimg.com/kq/groups/20981664/1536011611/name/ Dragiewicz+Lindgren+2009.pdf [visitado el 13/07/2013].

Facio Montejo, Alda, "Feminismo, Género y Patriarcado", en Violencia contra las mujeres, 37 pp. En: http://cidem-ac.org/sitio/documentos/_tastydir/d o.php?download=\%2Fhome $\% 2$ Fpangea $\% 2$ Fpublic_html\%2Fsitio\%2 Fd ocumentos $\% 2$ Fbibliovirtual\%2FVIOLENCIA $\% 20$ CONTRA $\% 20 L A S \% 20$ MUJERES\%2FGenero\%2C\%20Derecho\%20y\%20Patriarcado.pdf [visitado el 15/07/2013].

Gómez Tomillo, Manuel, "Derecho Penal Sexual y Reforma Legal: Análisis desde una perspectiva político criminal", Revista Electrónica de Ciencia Penal y Criminología, núm. 07-04, 2005, 35 pp. En: http://criminet.ugr.es/recpc/07/ recpc07-04.pdf [visitado el 16/07/2013].

GoldsCHeid, Julie, "Domestic and Sexual Violence as Sex Discrimination: Comparing American and International Approaches", Thomas Jefferson Law Review, volumen 8, número 3, 2006, pp. 355-398. En: http://www.tjeffersonlrev.org/sites/tjeffersonlrev.org/files/28-03-03-Goldscheid.pdf [visitado el 13/07/2013].

McQuigG, Ronagh J.A., "Domestic Violence and the Inter-American Commission on Human Rights: Jessica Lenahan (Gonzales) v United States", Human Rights Law Review, volumen 12, número 1, 2012, 13 pp. En: http://www. deepdyve.com/Ip/ou-press/domestic-violence-and-the-inter-americancommission-on-human-rights-NvMV0g65Yx?shortRental=true [visitado el 13/07/2013].

Londono, Patricia, "Developing Human Rights Principles in Cases of Genderbased Violence: Opuz v Turkey in the European Court of Human Rights", Human Rights Law Review, volumen 9, número 4, 2009, pp. 657-667. En: http://www.deepdyve.com/lp/oxford-university-press/developing-humanrights-principles-in-cases-of-gender-based-violence-0JsWtsQLNn [visitado el 13/07/2013].

Swan, Suzanne C. y Snow, David L., "A Typology on Women's Use of Violence in Intimate Relationships", Violence against women, volumen 8, número 3, 2002, pp. 286- 319. 
TJaden, Patricia y Thoennes, Nancy, "Prevalence. Incidence and Consequences of Violence Against Women: findings from the national violence against women survey", Research in Brief, 2, 1998, 16 pp. En: https://www.ncjrs. gov/pdffiles/172837.pdf [visitado el 18/07/2013].

\section{Convenciones}

Asamblea General de la Organización de Estados Americanos, Convención Interamericana para prevenir, sancionar y erradicar la violencia contra la mujer (Convención de Belem Do Para), 1994. En http://www.oas.org/juridico/ spanish/tratados/a-61.html [visitado el 13/07/2013].

Comité para la Eliminación de la Discriminación contra la Mujer, Convención sobre la Eliminación de Todas las Formas de Discriminación contra la Mujer (CEDAW), 1979. En: http://www2.ohchr.org/spanish/law/cedaw.htm [visitado el 17/07/2013].

\section{Documentos}

Comisión Interamericana de Derechos Humanos, Acceso a la Justicia para las Mujeres Víctimas de Violencia en las Américas, 2007. En: http://www.cidh. oas.org/women/Acceso07/indiceacceso.htm [visitado el 15/07/2013].

, Informe de la Comisión Interamericana sobre la Condición de la Mujer en las Américas, 1998. En: http://www.cidh.org/countryrep/Mujeres98/ Mujeres98.htm [visitado el 15/07/2013]. , Informe No 5/96, 1996. En: http://www1.umn.edu/humanrts/cases/1996/ Speru5-96.htm [visitado el 15/07/2013].

, Informe No 54/01, 2001. En: http://www.cidh.oas.org/annualrep/2000sp/ capituloiii/fondo/brasil12.051.htm [visitado el 16/07/2013].

, Informe sobre la Situación de los Derechos Humanos en Brasil, 1997. En: http://www.cidh.oas.org/countryrep/Brasesp97/indice.htm [visitado el 16/07/2013].

, Justicia e Inclusión Social: los desafíos de la democracia en Guatemala, 2003. En: http://www.cidh.org/countryrep/Guatemala2003sp/indice.htm [visitado el 15/07/2013].

, Las Mujeres Frente a la Violencia y la Discriminación Derivadas del Conflicto Armado en Colombia, 2006. En: http://www.cidh.org/countryrep/ colombiamujeres06sp/informe $\% 20$ mujeres $\% 20$ colombia $\% 202006 \% 20$ espanol.pdf [visitado el 15/07/2013].

, Segundo Informe sobre la Situación de los Derechos Humanos en Perú, 2000. En: http://www.cidh.org/countryrep/peru2000sp/indice.htm [visitado el 15/07/2013]. 
Situación de los Derechos de la Mujer en Ciudad Juárez, México: El Derecho a No Ser Objeto de Violencia y Discriminación, 2003. En: http://www. cidh.org/annualrep/2002sp/cap.vi.juarez.htm [visitado el 16/07/2013].

Comité para la Eliminación de la Discriminación contra la Mujer, Comunicación $N^{0}$ 1/2003, B.J. contra Alemania, 2004. En: http://www.worldcourts.com/cedaw/eng/decisions/2004.07.14_BJ_v_Germany.htm [visitado el 18/07/2013].

Comunicación № 2/2003, A. T. contra Hungría, 2005, pp. 395-401. En: http://www.un.org/womenwatch/daw/cedaw/protocol/decisions-views/ CEDAW\%20Decision\%20on\%20AT\%20vs\%20Hungary\%20Spanish.pdf, [visitado el 17/07/2013].

, Comunicación No 4/2004, A. S. contra Hungría, 2006. En: http://www. un.org/womenwatch/daw/cedaw/protocol/decisions-views/Decision $\% 20$ 4-2004\%20-\%20Spanish.pdf [visitado el 17/07/2013].

, Comunicación No 5/2005, Sahide Goekce contra Austria, 2007. En: http:// www.equidad.scjn.gob.mx/IMG/pdf/Caso_Sahide_Goekce_fallecida_v-_ Austria.pdf [visitado el 14/07/2013].

, Comunicación No 6/2005, Fatma Yildirim contra Austria, 2007. En http:// www.equidad.scjn.gob.mx/IMG/pdf/Caso_Fatma_Yildirim_fallecida_v-_Austria.pdf [visitado el 14/07/2013].

, Comunicación № 7/2005, Cristina Muñoz-Vargas y Sainz de Vicuña contra España, 2007. En: http://www.equidad.scjn.gob.mx/IMG/pdf/Caso_ Munoz_Vargas_v-_Espana_Inadmisible_.pdf [visitado el 17/07/2013].

Observaciones finales del Comité - CEDAW: Hungría. 23/08/2002. A/57/38, párr. 301-338. (Concluding Observations/Comments), 2002, párr. 321. En: http://www.acnur.org/biblioteca/pdf/5359.pdf?view=1 [visitado el 16/07/2013].

, Recomendación General № 19, 1992, párr. 6. En: http://www.ipu.org/ splz-e/cuenca10/cedaw_19.pdf [visitado el 17/07/2013].

Corte Penal Internacional, Las Reglas de Procedimiento y Prueba, 2000. En: http://www1.umn.edu/humanrts/instree/S-iccrulesofprocedure.html [visitado el 13/07/2013].

Organización Panamericana de la Salud, Modelo de Leyes y Políticas sobre Violencia Intrafamiliar contra las Mujeres, 2004. En: http://www1.paho.org/ Spanish/AD/GE/LeyModelo.pdf [visitado el 16/07/2013].

Organización de las Naciones Unidas, Proyecto de artículos sobre la responsabilidad del Estado por hechos internacionalmente ilícitos con sus comentarios, 2001. En: http://untreaty.un.org/ilc/texts/instruments/english/ commentaries/9_6_2001.pdf [visitado el 20/11/2011].

Programa de las Naciones Unidas para el Desarrollo, Integración del enfoque de género en los proyectos del PNUD, 2009. En: http://www.pnud.org.co/ 
img_upload/196a010e5069f0db02ea92181c5b8aec/ldeas\%20basicas.pdf [visitado el 18/09/2010].

Secretaría Ejecutiva de la Comisión Interamericana para el Control del Abuso de Drogas (CICAD) y Dirección General del Instituto Interamericano del Niño (IIN), La perspectiva de género como modelo de análisis de la violencia familiar y el consumo de alcohol y otras drogas, 1996. En: http://www.cicad. oas.org/reduccion_demanda/esp/Mujer/COSTARIC1996-rev.pdf [visitado el 20/08/2010].

\section{Libros}

Benites SÁnchez, Santiago, Derecho Penal Peruano: Comentarios a la Parte Especial, Imprenta del departamento de prensa y publicaciones de la Guardia Civil, Lima, 1959,193 pp.

Gimbernat Ordeig, Enrique, Sobre algunos aspectos del delito de violación en el Código Penal español: con especial referencia a la violación intimidatoria, Tecnos, Madrid, 1990 489-510 pp.

JaNIS, Mark Warren; KAY, Richard S; BRADleY, Anthony Wilfred, European Human Rights Law: Text and Materials, Oxford University Press, Oxford, 2008, 957 pp. En: http://books.google.com.co/books?id=T69A2ToYrOMC\&printsec=fr ontcover\&hl=es\&source=gbs_ge_summary_r\&cad=0\#v=onepage\&q\&f=fal se, [visitado el 16/07/2013].

\section{Sentencias}

A. con Croacia, Corte Europea de Derechos Humanos, Violencia doméstica, 14 de octubre de 2010. Demanda No 55164/08. En: http://echr.ketse.com/ doc/55164.08-en-20101014/view/ [visitado el 17/07/2013].

Comunidad Indígena Sawhoyamaxa con Paraguay, Corte Interamericana de Derechos Humanos, Responsabilidad internacional del Estado por no haber garantizado el derecho de propiedad ancestral de la Comunidad Sawhoyamaxa, Sentencia de 29 de marzo de 2006, Serie C No 146, 2006. En: http:// www.corteidh.or.cr/tablas/fichas/indigena_sawhoyamaxa.pdf [visitado el 16/07/2013].

Fernández Ortega y otros con México, Corte Interamericana de Derechos Humanos, Responsabilidad internacional por violación sexual cometida por agentes militares, 30 de agosto de 2010, Serie C № 216, 2010. En: http:// www.corteidh.or.cr/docs/casos/articulos/seriec_215_esp.pdf [visitado el 16/07/2013].

Fiscal con Kunarac, Kovac, Vukovic, Tribunal Penal Internacional para la Antigua Yugoslavia, Crímenes sexuales cometidos en un contexto de conflicto 
armado, 22 de febrero de 2001, Caso No IT-96-23-T \& IT-96-23/1-T, 2001. En: http://www.icty.org/x/cases/kunarac/tjug/en/kun-tj010222e.pdf [visitado el 17/07/2013].

Fiscal con Sesay, Kallon y Gbao, Tribunal Penal Internacional para Sierra Leona, Crímenes Internacionales de género, 26 de octubre de 2009, Caso № SCSL04-15-T, 2009. En: http://www.sc-sl.org/LinkClick.aspx?fileticket=CGgVJRf NF7M\%3D\&tabid=218 [visitado el 17/07/2013].

González y otras ("Campo Algodonero") con México, Corte Interamericana de Derechos Humanos, Responsabilidad internacional del Estado por la falta de diligencia en las investigaciones relacionadas a la desaparición y muerte de Claudia Ivette González, Esmeralda Herrera Monreal y Laura Berenice Ramos Monárrez, 16 de noviembre de 2009, Serie C No 205, 2009. En: http://www.corteidh.or.cr/tablas/fichas/campoalgodonero.pdf [visitado el 16/07/2013].

Kilic con Turquía, Corte Europea de Derechos Humanos, Responsabilidad estatal por violencia de género, 28 de marzo de 2000, Demanda No 22492/93. En: http://www.humanrights.is/the-human-rights-project/humanrightscasesandmaterials/cases/regionalcases/europeancourtofhumanrights/nr/547 [visitado el 24/11/2010].

Masacre de Pueblo Bello con Colombia, Corte Interamericana de Derechos Humanos, Masacre y secuestros realizados por una organización paramilitar en el corregimiento de Pueblo Bello, 31 de enero de 2006, Serie C No 140, 2006. En: http://www.corteidh.or.cr/docs/casos/Artículos/seriec_140_esp. doc [visitado el 16/07/2013].

MC con Bulgaria, Corte Europea de Derechos Humanos, Obligación del Estado de investigar efectivamente y tipificar adecuadamente la violación sexual, 4 de diciembre de 2003, Solicitud No 39272/98, 2003. En: http://www.coe. int/t/dg2/equality/domesticviolencecampaign/resources/m.c.v.bulgaria_ EN.asp [visitado el 17/07/2013].

Opuz con Turquía, Corte Europea de Derechos Humanos, Violencia doméstica como una violación a los derechos humanos y una forma de discriminación, 9 de junio de 2009, Demanda No 33401/02, 2009. En: http://www. coe.int/t/dghl/standardsetting/minjust/mju29/CASE\%20OF\%20OPUZ\%20 v\%5B1\%5D.\%20TURKEY.pdf [visitado el 23/10/2010].

Osman con Reino Unido, Corte Europea de Derechos Humanos, Deber de prevención, 28 de octubre de 1998, Demanda No 23452/94. En: http://www. bailii.org/eu/cases/ECHR/1998/101.html [visitado el 24/11/2010].

Penal Miguel Castro Castro con Perú, Corte Interamericana de Derechos Humanos, Responsabilidad Internacional del Estado por utilización excesiva de la fuerza, 25 de noviembre de 2006, Serie C No 160, 2006. En: http:// 
www.corteidh.or.cr/docs/casos/articulos/seriec_160_esp.pdf [visitado el 16/07/2013].

Perozo y otros con Venezuela, Corte Interamericana de Derechos Humanos, Responsabilidad internacional del Estado por restricciones a la libertad de expresión, 28 de enero de 2009, Serie C No 195, 2009. En: http://www. corteidh.or.cr/tablas/fichas/perozo.pdf [visitado el 16/07/2013].

Ríos y otros con Venezuela, Corte Interamericana de Derechos Humanos, Responsabilidad internacional del Estado por las restricciones a la libertad de expresión en perjuicio de 20 trabajadores del canal de televisión RCTV, 28 de enero de 2009, Serie C No 194. En: http://www.corteidh.or.cr/tablas/ fichas/rios.pdf [visitado el 16/07/2013].

Rosendo Cantú y otra con México, Corte Interamericana de Derechos Humanos, Responsabilidad internacional del Estado por violación sexual y tortura en perjuicio de la señora Rosendo Cantú, 31 de agosto de 2010, Serie C № 216, 2010. En: http://www.corteidh.or.cr/docs/casos/articulos/seriec_216_esp.pdf [visitado el 16/07/2013].

Primera Sala de la Suprema Corte de Justicia de la Nación, Violación sexual entre cónyuges, 16 de noviembre de 2005, Gaceta del Semanario Judicial de la Federación, Núm. 77, 2005. En: http://ius.scjn.gob.mx/documentos/ tesis/206/206112.pdf [visitado el 15/07/2013].

Valle Jaramillo y otros con Colombia, Corte Interamericana de Derechos Humanos, Responsabilidad internacional del Estado por la ejecución extrajudicial de Jesús Valle Jaramillo, 27 de noviembre de 2008, Serie C № 192, 2008. En: http://www.corteidh.or.cr/tablas/fichas/vallejaramillo.pdf [visitado el 16/07/2013].

Woods con Horton, California Third District Court of Appeal, Domestic Violence, 14 de octubre de 2008, 84 Cal. Rptr. 3d 332, 349.

X e Y con Países Bajos, Corte Europea de Derechos Humanos, Violación sexual de una adolescente con discapacidad mental como una violación a los derechos humanos, 26 de marzo de 1998, Serie A No 91, 1985. En: http:// www.juridischeuitspraken.nl/19850326EHRMXenYtegenNederland.pdf [visitado el 15/09/2010].

\section{BibLIOGRAFÍA CONSULTADA}

CARO CorIA, Dino Carlos, Imputación Objetiva, delitos sexuales y reforma penal, Instituto de Investigaciones Jurídicas, México, 2002, 155 pp.

Organización de las Naciones Unidas, Convención de Viena sobre el Derecho de los Tratados, 1969. En: http://www.derechos.org/nizkor/ley/viena.html [visitado el 22/12/2010]. 
Comisión Interamericana de Derechos Humanos (1996), Informe No 38/96, 1996. En: http://www.cidh.oas.org/annualrep/96span/Argentina10506.htm [visitado el 16/07/2013].

Comisión Interamericana de Derechos Humanos, Informe N 53/01, 2001. En: http://www.cidh.org/annualrep/2000sp/capituloiii/fondo/Mexico11.565.htm [visitado el 17/07/2013].

Informe $\mathrm{N}^{\circ}$ 4/01, 2001. En: http://www.cidh.oas.org/annualrep/2000sp/ CapitulollI/Fondo/Guatemala11.625.htm [visitado el 17/07/2013].

Bevacqua y S. con Bulgaria, Corte Europea de Derechos Humanos, Violencia doméstica, 12 de junio de 2008, Demanda No 71127/01, 2008, 23 pp. En: http://www1.umn.edu/humanrts/research/bulgaria/BEVACQUA.pdf [visitado el 17/07/2013].

Fiscal con Zejnil Delalic, Zdravko Mucic, Hazim Delic and Esad Landzo, Tribunal Penal para la Antigua Yugoslavia, Violencia sexual en un contexto de conflicto armado, 16 de noviembre de 1998, Caso No IT-96-21-T, 1998. En: http://www.icty.org/x/cases/mucic/tdec/en/61111PN4.htm [visitado el 17/07/2013].

Fiscal con Jean Paul Akayesu, Tribunal Penal Internacional para Rwanda, Genocidio, 2 de septiembre de 1998, Caso No ICTR-96-4-T, 1998. En: http:// www.unictr.org/Portals/0/Case/English/Akayesu/judgement/akay001.pdf [visitado el 17/07/2013].

Fiscal con Laurent Semanza, Tribunal Penal Internacional para Rwanda, Violencia sexual en un contexto de conflicto armado no internacional, 15 de mayo de 2003, Caso No ICTR-97-20-T, 2003. En: http://www1.umn.edu/ humanrts/instree/ICTR/SEMANZA_ICTR-97-20/SEMANZA_ICTR-97-20-T. htm [visitado el 17/07/2013].

Masacre de las Dos Erres con Guatemala, Corte Interamericana de Derechos Humanos, Responsabilidad internacional del Estado por falta de debida diligencia en la investigación, juzgamiento y sanción de los responsables del asesinato, tortura, violación sexual, entre otros actos en perjuicio de numerosas personas habitantes del parcelamiento de las Erres, por parte de agentes militares, 24 de noviembre de 2009, Serie C No 211, 2009, 93 pp. En: http://www.corteidh.or.cr/docs/casos/articulos/seriec_211_esp.pdf [visitado el 17/07/2013]. 